\title{
A balanced Kalman Filter ocean data assimilation system with application to the South Australian Sea
}

\author{
Yi Li ${ }^{\mathrm{a}, *}$, Ralf Toumi ${ }^{\mathrm{a}}$ \\ ${ }^{a}$ Space and Atmospheric Physics Group, Department of Physics, Imperial College London
}

\begin{abstract}
In this paper, an Ensemble Kalman Filter (EnKF) based regional ocean data assimilation system has been developed and applied to the South Australian Sea. This system consists of the data assimilation algorithm provided by the NCAR Data Assimilation Research Testbed (DART) and the Regional Ocean Modelling System (ROMS). We describe the first implementation of the physical balance operator (temperature-salinity, hydrostatic and geostrophic balance) to DART, to reduce the spurious waves which may be introduced during the data assimilation process. The effect of the balance operator is validated in both an idealised shallow water model and the ROMS model real case study. In the shallow water model, the geostrophic balance operator eliminates spurious ageostrophic waves and produces a better sea surface height (SSH) and velocity analysis and forecast. Its impact increases as the sea surface height and wind stress increase. In the real case, satelliteobserved sea surface temperature (SST) and SSH are assimilated in the South Australian Sea with 50 ensembles using the Ensemble Adjustment Kalman Filter (EAKF). Assimilating SSH and SST enhances the estimation of SSH and SST in the entire domain, respectively. Assimilation with the balance operator produces a more realistic simulation of surface currents and subsurface temperature profile. The best improvement is obtained when only SSH is assimilated with the balance operator. A case study with a storm suggests that the benefit of the balance operator is of particular importance under high wind stress conditions. Implementing the balance operator could be a general benefit to ocean data assimilation systems.
\end{abstract}

\footnotetext{
* Corresponding author

Email address: y.li14@imperial.ac.uk (Yi Li)
} 
Keywords:

ROMS, EnKF, multivariate balance

2

\section{Introduction}

By using the Bayesian theorem, data assimilation provides an objective criterion for fusing observations with numerical models to produce an estimate of the true state (e.g. Lahoz and Schneider, 2014; Wikle and Berliner, 2007). This is a crucial step in providing an optimal initial condition for ocean forecasting (e.g. Lahoz and Schneider, 2014; Blayo et al., 2014). Global ocean data assimilation has developed rapidly during the past decade, and an increasing number of products are provided by groups worldwide (e.g., Global Ocean Data Assimilation Experiment, https: //www.godae-oceanview .org/). However, the typical resolution of global models is still too low to resolve mesoscale features thus there is a need to develop regional ocean data assimilation systems (Moore et al., 2013).

There are two popular data assimilation approaches: variational and sequential (Lahoz and Schneider, 2014). The variational approach adjusts the model trajectories to fit the observations by minimising the cost function. On the other hand, the sequential approach updates the model state by comparing the mean and variability of both model and data, each time when the new observation is available. These two approaches are both based on the Bayesian theorem and can be simplified to similar algorithms under the assumptions of Gaussianity and linearity. The detailed description of data assimilation algorithms has been explored extensively (e.g. Lahoz and Schneider, 2014; Wikle and Berliner, 2007; Evensen, 2009).

The Kalman Filter (Kalman, 1960) is a sequential data assimilation algorithm designed for a linear dynamical model with Gaussian-distributed model and observation errors. Evensen (1994) developed the ensemble method by using a Monte Carlo technique to approximate the mean and covariance of a high-dimensional system. Compared with the variational data assimilation such as four-dimensional variational method (4DVAR), EnKF needs much less effort to implement since the tangent linear and adjoint models are not needed. It is also possible to use different physical schemes in the ensemble members.

EnKF has been used in several regional ocean data assimilation studies. Evensen and van Leeuwen (1996) developed the first EnKF based regional 
data assimilation system for the Agulhas current using a quasigeostrophic model. Seo et al. (2010) assimilated SST in a northwest Pacific ROMS model through a stochastic EnKF scheme, but only SST was assimilated and physical balance was not studied. Here we present the first implementation of DART (Anderson et al., 2009), a community data assimilation facility to ROMS, to provide several state-of-the-art algorithms with localisation, inflation techniques. Also, we use balance constraints to reduce the spurious waves generated in the data assimilation process.

The localisation technique is needed to reduce the harm caused by the spurious covariances with distant grid points in EnKF with limited ensemble members (Lorenc, 2003; Houtekamer and Mitchell, 2001; Gaspari and Cohn, 1999). However, localisation may cause imbalance to the dynamical system (Lorenc, 2003; Greybush et al., 2011), although a balanced model error covariance produces balanced analysis state (Cohn and Parrish, 1991). Lorenc (2003) pointed out that when SSH observation at a single point is assimilated without localisation, the increments of SSH and ocean currents are balanced. If localisation is used, the gradient of SSH increases while the ocean currents reduce. Therefore spurious ageostrophic waves are created in this process. A schematic description of this example can be found in Greybush et al. (2011) (in their Fig. 1). Mitchell et al. (2002) reported that different ensemble size, assimilating frequency or localisation radius can cause imbalance for GCMs. Kepert (2009) suggested using localisation of streamfunction and velocity potential instead of $u$ and $v$ velocities, but this method is not easy to implement for regional ocean models. For the multivariate problem, it is also difficult to specify the relationship among various variables. A common practice is to use linear regression, but this can be a major source of error (Anderson, 2007b). To solve this problem, Anderson (2007b) proposed to 'localise' the impact of observation to model states (e.g., SST observation at one point and simulated ocean currents at another point), but he also pointed out that it is usually difficult to define the 'distance' between them, especially for high-dimensional GCMs. In this paper, we use a multivariate balance operator proposed by Weaver et al. (2005) to solve the imbalance problem. In this algorithm, each model variable is separated into balanced and unbalanced components, and several balance assumptions are made to calculate the increments. This physical constraint has been used in several variational ocean data assimilation systems (e.g. Balmaseda et al., 2013; Li et al., 2008; Moore et al., 2011c).

The DART/ROMS data assimilation system is applied to the South Aus- 
tralian Sea $\left(31.5^{\circ} \mathrm{S}\right.$ to $39.5^{\circ} \mathrm{S}, 117^{\circ} \mathrm{E}$ to $\left.140^{\circ} \mathrm{E}\right)$. This region hosts the world's longest zonal, mid-latitude shelf (about 2500km) between Cape Leeuwin and Portland (Middleton and Bye, 2007). The Leeuwin Current, flowing southward from the tropics near the west coast of Australia, enters the South Australian Sea around Cape Leeuwin and extends to Tasmania. This region is recognised as one of the 64 Large Marine Ecosystems (LMEs) by NOAA (http://www.lme.noaa.gov/). There are also emerging tourism ventures and oil/gas exploration. The simulation and prediction of the ocean circulation, temperature and other oceanic variables are therefore necessary.

In this paper, we first describe the data assimilation system and the balance operator in Section 2. In Section 3 we evaluate the effect of balance operator using an idealised two-dimensional shallow water model. The results of the South Australian Sea model are given in Section 4. In Section 5 we discuss and analyse the results from Section 3 and 4. A summary concludes this paper in Section 6.

\section{Method and data}

The Ensemble Adjustment Kalman Filter (EAKF) (Anderson, 2001) is implemented as the data assimilation algorithm. We introduce a physical balance operator to this system and analyse the performance in both an idealised shallow water model and the ROMS real case.

\subsection{Ensemble Kalman Filter and the balance operator}

There are many implementations of the ensemble Kalman Filter (e.g. Evensen, 2003; Houtekamer and Mitchell, 2001; Anderson, 2001). The data assimilation cycle consists of two stages. Firstly, in the forecasting stage, the model state $x$ evolves through a dynamic model and secondly in the analysis stage the estimation of model state is improved by comparing the forecast $x^{f}$ and the observation $y^{o}$, the analysis is computed as,

$$
x^{a}=x^{f}+K\left[y^{o}-H\left(x^{f}\right)\right],
$$

where $B$ is the model error covariance matrix, $R$ is the observation error covariance. $H$ is the observation operator that projects the model state $x$ to the observation space $y=H(x)$. The difference between $x^{a}$ and $x^{f}$ is defined as the increment $\Delta x$. The optimal variance minimising weight is given by the Kalman gain, 


$$
K=B H^{T}\left(H B H^{T}+R\right)^{-1},
$$

In the ensemble data assimilation approach, the $B$ matrix is computed from the $N$ ensemble members in each data assimilation cycle as,

$$
B=X^{f} X^{f T},
$$

where $X=\frac{1}{\sqrt{N-1}}\left(x_{1}-\bar{x}, x_{2}-\bar{x}, \ldots, x_{N}-\bar{x}\right)$ is the perturbation matrix whose columns are the deviations from the ensemble mean.

For an ocean model such as ROMS, there are 5 components in the state vector $x$ : sea surface height $\eta$; potential temperature $T$; salinity $S$; horizontal velocities $u$ and $v$. Temperature is usually the most observed variable in the ocean so Weaver et al. (2005) proposed to compute the relations between the variables based on $T$. Each variable except $T$ is decomposed into two components, the balanced component and the unbalanced one. Therefore the perturbations $\delta x$ can also be decomposed as following,

$$
\left(\begin{array}{c}
T \\
S \\
\eta \\
u \\
v
\end{array}\right)=\left(\begin{array}{c}
T \\
S_{B} \\
\eta_{B} \\
u_{B} \\
v_{B}
\end{array}\right)+\left(\begin{array}{c}
0 \\
S_{U} \\
\eta_{U} \\
u_{U} \\
v_{U}
\end{array}\right)=L\left(\begin{array}{c}
T \\
S_{U} \\
\eta_{U} \\
u_{U} \\
v_{U}
\end{array}\right)
$$

where the variables with subscript $B$ represent the balanced component of the variables while those with subscript $U$ represent the unbalanced one. The balanced part of variable $x_{1}$ can be derived from other variable $x_{2}$ through the linear balance operator $L$. The details of $L$ are explained in Appendix A.

The model error covariance is thus converted to,

$$
B=L B_{u} L^{T}
$$

and Eq.1 is written as,

$$
x^{a}=x^{f}+L B_{u} L^{T} H^{T}\left(H L B_{u} L^{T} H^{T}+R\right)^{-1}\left[y^{o}-H\left(x^{f}\right)\right],
$$

where $B_{u}$ is the error covariance of the unbalanced components. Here we assume that the balanced components of the ocean state are correlated while the unbalanced residuals are uncorrelated (Weaver et al., 2005). 
An update scheme is designed based on this algorithm. This scheme starts from an ensemble of initial model states or short-term forecast, then the balanced component is calculated and the unbalanced component is derived. $B_{u}$ is computed from the unbalanced component, after which the model states are updated using Eq.6 (Fig. 1).

\subsection{Shallow water model}

The prediction of ocean currents is of particular interest and satellite observed SSH is the most widely used variable in data assimilation systems to constrain the ocean currents (e.g. Jacobs et al., 2014). It is necessary to validate the effect of the geostrophic balance operator on ocean currents. Here we use a two-dimensional shallow water model to initially evaluate the effect of the balance operator. The shallow water equations describe a rotating (with constant Coriolis parameter), inviscid fluid with wind forcing in the $x$ direction. Similar shallow water models have been used to study the physical balance (e.g. Kepert, 2009; Greybush et al., 2011). The model equations are,

$$
\begin{aligned}
& \frac{\partial u}{\partial t}+u \frac{\partial u}{\partial x}+v \frac{\partial u}{\partial y}-f v+\tau=-g \frac{\partial \eta}{\partial x} \\
& \frac{\partial v}{\partial t}+u \frac{\partial v}{\partial x}+v \frac{\partial v}{\partial y}+f u=-g \frac{\partial \eta}{\partial y} \\
& \frac{\partial \eta}{\partial t}+\frac{\partial}{\partial x}[u(h+\eta)]+\frac{\partial}{\partial y}[v(h+\eta)]=0
\end{aligned},
$$

where $\eta$ is the free surface displacement, $h$ is the bottom topography $(50 \mathrm{~m}$ in this experiment), $\tau$ is the wind forcing, and $f$ is the Coriolis parameter. We set the Coriolis parameter to $10^{-4} \mathrm{~s}^{-1}$, a typical value for the mid-latitude. The model is constructed on a 2000 by $2000 \mathrm{~km}$ domain with $10 \mathrm{~km}$ horizontal resolution in both $\mathrm{x}$ and $\mathrm{y}$ direction and forced by periodic boundary conditions.

Each ensemble is initialised from meridional $\eta$ ridges,

$$
\eta(x)=\eta_{0} \cos \left(\frac{2 \pi}{L}\left(x-x_{p s}\right)\right),
$$

where $L$ is the wavelength and in the true state $L$ is set to $200 \mathrm{~km}, \eta_{0}$ is the amplitude and $x_{p s}$ is the wave phase shift. Each ensemble is forced by a periodic zonal wind stress $\tau$ with a period of 48 hours, 


$$
\tau(t)=\tau_{0} \cos \left(\frac{2 \pi}{t_{\tau}}\left(t-t_{p s}\right)\right)
$$

where $\tau_{0}$ is the amplitude, $t_{\tau}$ is the period (48 hours), and $t_{p s}$ is the wave phase shift. The initial sea surface height of each ensemble member is generated by shifting the phase of the true initial state $x_{p s}$ by a uniform random distribution of $[20,40] \mathrm{km}$ and the amplitude $\eta_{0}$ by $[-0.05,0.05] \mathrm{m}$. In the initial condition of the true state and each ensemble member, the velocities are calculated according to the geostrophic balance. The wind forcing of each ensemble member is perturbed by randomly shifting the amplitude by $[-10 \%, 10 \%]$ and the phase by $[-3,3] \mathrm{hr}$. A schematic setup of the model is displayed in Fig. 2.

We first integrate the true state through a Lax-Wendroff scheme, with a time step $6 \mathrm{~s}$, for 576000 steps, or 40 days. The observations of $\eta$ are then created by adding a Gaussian distributed white noise with 0 m mean and 0.03 $m$ standard deviation to the true state. The locations of the observations are selected along 4 diagonal tracks with a $10 \mathrm{~km}$ interval to mimic the satellite tracks. The period of the observations is set to 24 hours, and the observation tracks move eastward at a $3000 \mathrm{~km} /$ day speed similar as the real satellite tracks. We conduct two sets of experiments by varying the initial SSH and wind stress, as described in Table. 1. In both the shallow water case and the ROMS real case, a background covariance matrix localisation technique (Gaspari and Cohn, 1999) is used. Two localisation scales (60 km and 100 $\mathrm{km}$, the scale is the halfwidth of the Gaspari Cohn parameter in this paper, as the default setup in DART) are used in the idealised case. Larger scales have been tested but the resulting SSH and velocity fields are over-smoothed and thus not used here. In each experiment, the ensemble size is set to 100 and the error of the observations is set to $0.03 \mathrm{~m}$. Each experiment is integrated for 40 days by assimilating sea surface height only with a 24-hour assimilation window and the results of the last 30 days are analysed.

\subsection{Application of the ROMS/DART system in the South Australian Sea 2.3.1. Configuration of DART}

DART is 'an open-source community facility that provides software tools for data assimilation research, development, and education' (Anderson et al., 2009) developed and maintained by the Data Assimilation Research Section (DAReS) at the National Center for Atmospheric Research (NCAR). DART provides several deterministic and stochastic algorithms, including Ensemble 
Adjustment Kalman, Ensemble Kalman, Kernel and Particle filters. These algorithms have been used in different atmosphere and ocean general circulation models (Anderson et al., 2009) including both regional (MITgcm) (Hoteit et al., 2013) and global (POP) (Karspeck et al., 2013) ocean models.

One of the major problems facing the traditional EnKF is that the ensemble size is usually too small to calculate the statistics. In this paper, a deterministic algorithm, the Ensemble Adjustment Kalman Filter (EAKF) (Anderson, 2001, 2003) is used. EAKF is a type of ensemble square root filter (Tippett et al., 2003) and in this algorithm the model state is computed through an adjustment matrix so that the posterior covariance satisfies the Kalman gain exactly.

Assimilation of each observation adds information to the dynamic system and thus the spread of the ensemble decreases. This reduction of ensemble spread could be problematic due to the model and observation error and bias. The problem is addressed in DART by inflating the spread periodically. The inflation must vary spatially and temporally to improve analysis and forecast. DART employs a hierarchical Bayesian filter (HBF) adaptive inflation algorithm (Anderson, 2007a) to produce varying inflation. If the observation is further from the ensemble mean than expected, HBF uses more inflation and vice versa. In the ROMS case, only prior inflation is used and the inflation is assigned with initial value of 1.02, the lowerbound of 1.0, the inflation damping of 0.9 and evolves with the standard deviation of 0.6 . In most of the experiments, the actual inflation coefficient is 1 to 6 , which is a reasonable value. In the idealised shallow water model, no inflation is used.

Another challenge for ensemble methods with small ensemble size is the spurious long-distance correlations (Houtekamer and Mitchell, 1998). The localisation technique is usually used to suppress the influence of distant observations (e.g. Mitchell et al., 2002). The optimum choice of the localisation scale depends on several factors such as the ensemble size (e.g. Mitchell et al., 2002) and sampling correlation (e.g. Emerick and Reynolds, 2011). The localisation radius halfwidth is set to 0.03 arc in the ROMS case, which is about $110 \mathrm{~km}$ in the region. This value is selected after comparing a series of assimilation experiments (not shown here) with different localisation configurations (0.02 arc, 0.03 arc, 0.04 arc and 0.05 arc). Generally, a larger scale produces a better result for SSH while a smaller one produces better SST. The results with the scale of 0.03 arc are overall the best for both variables.

The initial state ensemble is essential for the success of data assimilation as it provides information about the variability and uncertainty of the system. 
An appropriate initial ensemble should include 'information about the main physical quantities that govern the evolution of the state' thus it could speed up convergence toward the 'true' ocean state (Hoteit et al., 2008). Following Hoteit et al. (2013), a second-order sampling scheme (Pham, 2001) is used to generate the initial ensemble. Firstly, we create a set of model states using the results of the control run (in this study, a 7 year control run, as described in the following section) in winter since the South Australian Sea is dominated by strong seasonality (Middleton and Bye, 2007). Secondly, an Empirical Orthogonal Function (EOF) analysis is applied to extract the dominant variability from this long model trajectory. Then the initial states are generated using the following equation,

$$
x_{0}^{i}=\bar{x}+\sqrt{N} L_{0} \sigma_{i}^{T},
$$

where $N$ is the ensemble size, $L_{0}$ is the matrix whose $N-1$ columns are the EOFs, $\bar{x}$ is the mean of the long-term trajectory and $\sigma_{i}$ is the $i$ th of a $(N-1) \times N$ random matrix with orthonormal columns and zero column sums. The ensemble size is determined according to the limitation of computation resource and model variance, in this study the ensemble size is 50 . The ensemble members are thus generated with mean $\bar{x}$ and covariance matrix $L_{0} L_{0}^{T}$ which is an optimum approximation of the original states (Hoteit et al., 2013). The ensemble is then used to initialise DART.

\subsubsection{Configuration of $R O M S$}

ROMS is a free-surface, hydrostatic, primitive equations ocean model with a terrain-following coordinate system (Haidvogel et al., 2008; Shchepetkin and McWilliams, 2005, 2009). It has been widely used for a diverse range of applications (e.g. Haidvogel et al., 2000; White and Toumi, 2014; Wilkin et al., 2005). In addition, ROMS is one of the few community ocean models which support 4D-VAR (e.g. Moore et al., 2011a,b,c; Song et al., 2012).

The ROMS model is implemented in the South Australian Sea on a $10 \mathrm{~km}$ horizontal grid with 35 vertical layers. The vertical coordinate is set to a minimum depth of $5 \mathrm{~m}$ and a maximum depth of $5000 \mathrm{~m}$. The 4th-order centred vertical advection and 3rd-order upstream horizontal advection schemes are used for tracer advection. The horizontal advection of momentum is calculated using a 3rd-order upstream split scheme with the Smagorinsky-like viscosity applied, and the vertical advection of momentum is calculated using a splines scheme. The model domain extends 
from $39.5^{\circ} \mathrm{S}$ to $31.5^{\circ} \mathrm{S}$ and $117^{\circ} \mathrm{E}$ to $140^{\circ} \mathrm{E}$. The bathymetry is obtained from the Scripps Institute of Oceanography global seafloor topography (Smith, 1997). Tidal sea level and horizontal velocity are extracted from Oregon State University TPXO7.2 global inverse tidal model at $1 / 12^{\circ}$ resolution (http://volkov.oce.orst.edu/tides/global.html). The initial and lateral boundary conditions for temperature, salinity, three-dimensional velocity fields, and non-tidal sea level are obtained from the daily mean, $1 / 12^{\circ}$ HYCOM re-analysis (Metzger et al., 2014). The model is forced with the 6-hourly re-analysis atmospheric state from the National Centers for Environmental Prediction (NCEP) Climate Forecast System Re-analysis (CFSR) project (Saha et al., 2010). The atmospheric forcing variables include downward longwave radiation, downward shortwave radiation, sea level pressure, $2 \mathrm{~m}$ specific humidity, $2 \mathrm{~m}$ air temperature, $10 \mathrm{~m}$ winds, and total precipitation. Climatological river discharge is obtained from RivDIS database (Vorosmarty et al., 1998) provided by KNMI (http://climexp.knmi.nl/) to calculate the flow rate of the major river (River Murray) in this region.

\subsubsection{Experiment design}

The control simulation runs for 8 years from 2005 to 2012. The first year is discarded as the spin-up period. The data assimilation simulations all run from January 2007 to June 2007. In the data assimilation experiments, the AVISO along-track sea surface height (SSH) anomalies (http://www . aviso . altimetry.fr/en/home.html) and TMI along-track sea surface temperature (SST) dataset (http://www.remss.com/missions/tmi) are assimilated every five days. Here all observations within \pm 2.5 days of the assimilation time are binned as if they were available at the middle of this assimilation window. This window length is similar with previous studies (e.g. Hoteit et al., 2013; Oke et al., 2013). The main variability from the 30 year CFSR data for each month are extracted using EOF analysis and the atmospheric forcing for each of the ensemble members is created in a similar way as the initial ensembles,

$$
x^{i}=x+0.2 * \sqrt{N} L \sigma_{i}^{T},
$$

where $x$ is the forcing variables (wind field and radiation in this paper), $L$ is the EOF matrix of the 30 year (1981-2010) data during the appropriate month of the forcing, and $\sigma_{i}$ is the random matrix as described in Eq. 10. Thus the forcing for each ensemble member is different, and the error of 
CFSR is assumed to be 20\%. The open boundary forcing is from HYCOM analysis and unvaried.

AVISO merges observations from different satellites but only Jason-1, Geosat and Envisat were operating during our data assimilation period. Following Moore et al. (2011a), the AVISO data is processed before being assimilated by adding the observed sea level anomalies to the difference between the ROMS mean SSH and AVISO dynamic topography for 2006-2012 to remove the offset between the model SSH and AVISO dynamic topography. Because the AVISO SSH data is de-tided, we use the FES2012 tidal model (Lyard et al., 2006) to add the tidal signal to the original AVISO SSH. The water levels simulated by ROMS and FES2012 model are similar in most of the domain, but in regions where the ocean is shallow and bathymetry is complicated, they are different. Therefore the data within $100 \mathrm{~km}$ distance of the coastline is discarded. TMI (TRMM Microwave Imager) is one of the 5 instruments carried by TRMM (the Tropical Rainfall Measuring Mission), which launched on 27 November 1997. TMI measures SST in addition to rainfall, sea surface wind speed, column water vapour and cloud liquid water. The SST data within $100 \mathrm{~km}$ distance to the coastline is considered not reliable (Hoteit et al., 2013) and is discarded. 5 data assimilation experiments are carried out to assimilate SST and SSH with/without balance operator. The setup of all experiments is summarised in Table 2.

We use both gridded data products and direct observations to evaluate the effect of data assimilation. The comparison with gridded products, including AVISO $1 / 4^{\circ}$ gridded daily dynamic topography, OISST version 2 daily SST data and Ocean Surface Current Analysis Real-time (OSCAR; Bonjean and Lagerloef, 2002) currents, illustrates the effects over the whole domain. The AVISO gridded data is processed similarly to the along track data to ensure the spatiotemporal mean of AVISO and model SSH are equal. The OISST data composites observations from different platforms (satellites, ships, buoys) on a $1 / 4^{\circ}$ global grid and the gaps are filled by interpolation (Reynolds et al., 2007). The OSCAR data provides $1 / 3^{\circ} 5$-day mean near real-time global ocean currents products of the top $30 \mathrm{~m}$ calculated from satellite altimetry and wind fields. Although the more complex physical process is missing, OSCAR provides 'as close to a direct satellite measurement of surface currents on a fixed global grid at regular intervals as possible' (Dohan and Maximenko, 2010). Ocean surface currents from 7 drifters (2791 data points) (http://www.aoml.noaa.gov/phod/dac/gdp_drifter.php; Lumpkin and Pazos, 2007) and subsurface temperature and salinity observed by 
8 Argo floats (198 profiles) are also used to provide independent validation. The ARGO floats were located around $120^{\circ} \mathrm{E}, 25.5^{\circ} \mathrm{S}$ and the drifters were distributed in the south part of the domain (Fig. 5).

\section{Results}

\subsection{Shallow water model}

Lorenc (2003) pointed out that assimilating SSH in a shallow water model creates spurious ageostrophic waves. Fig. 3 shows the increments at the 25th data assimilation cycle with $0.2 \mathrm{~Pa}$ wind stress and $100 \mathrm{~km}$ localisation radius. The increment in the unbalanced experiment is strongly ageostrophic (Fig. 3(B)) while in the balanced experiment there is no ageostrophic current increment. The localisation reduces both SSH and velocities proportionally but increases the SSH gradient. In addition, the wind forcing creates ageostrophic currents in the prior state and, in the unbalanced experiment, this signal propagates to the increment through the multivariate regression. Therefore, a spurious ageostrophic shock is created in the posterior state and this affects the performance of data assimilation. Theoretically, the dynamical model is able to adjust and restore to a balanced state even it starts with spurious waves. However, this restored state is different from the one starting from a balanced state (not shown). In addition, this geostrophic adjustment in the dynamical model is usually not fast enough. The ageostrophic currents in the 24 hour forecast is stronger by around $3 \mathrm{~cm} / \mathrm{s}$ in the unbalanced experiment than in the balanced experiment, when the wind stress is $0.2 \mathrm{~Pa}$. Thus the balance operator is needed to reduce the misfit between the truth and assimilations in different scenarios.

The balance operator reduces the error of different variables in varying wind forcing and initial SSH displacement scenarios. Here we use the Root Mean Square Error (RMSE) between the simulation and the true state as the metric for evaluating the assimilation. Fig. 4(a) and (b) display the RMSE of SSH and $v$ velocity as a function of initial $\eta$ amplitude (the amplitude does not change much in the integration), respectively. It is evident that the data assimilation with the balance operator produces a lower error for both sea surface height and velocity estimation compared to the unbalanced approach. Although the RMSE increases as the amplitude increases, the relative advantage of the balance operator also increases. In addition, a longer localisation radius is better than a shorter one for either method. However, 
the balanced method with smaller localisation radius outperforms the original method with the larger radius. When both use a larger radius $(100 \mathrm{~km})$, the balanced data assimilation produces a 17\% lower average RMSE than the unbalanced approach $(5.2 \mathrm{~cm}$ and $6.2 \mathrm{~cm}$ respectively) for the $\mathrm{SSH}$ and $11 \%$ for the $\mathrm{v}$ velocity $(16 \mathrm{~cm} / \mathrm{s}$ and $18 \mathrm{~cm} / \mathrm{s}$ respectively).

When forced by varying wind stress, the balance operator also improves the data assimilation performance although the error in both experiments is higher than that with fixed wind forcing, because of the noisy forcing (Fig. 4(c) and (d)). With a $100 \mathrm{~km}$ localisation radius, the average error of $\mathrm{SSH}$ decreases $12 \%$ from 4.2 to $3.7 \mathrm{~cm}$ and the error of $v$ reduces $9 \%$ from $22 \mathrm{~cm} / \mathrm{s}$ to $20 \mathrm{~cm} / \mathrm{s}$. In the ocean, the typical value of SSH is around 10 to 20 $\mathrm{cm}$ while the wind stress is around $0.1 \mathrm{~Pa}$. In those conditions, the balance operator reduces the RMSE of SSH and velocity by $12 \%$ (from $2.3 \mathrm{~cm}$ to $2.0 \mathrm{~cm}$ ) and $7 \%$ (from $13 \mathrm{~cm} / \mathrm{s}$ to $12 \mathrm{~cm} / \mathrm{s}$ ), respectively. The effect of the balance operator is more significant when the wind stress is larger. This is because the ageostrophic component in the prior ensembles increases as the wind stress increases, thus the increments of ageostrophic current in the unbalanced experiment get stronger. For example, when the wind stress is as large as $0.3 \mathrm{~Pa}$ the error increases significantly and the advantage of the balance operator is $17 \%$ and $11 \%$ for $\eta$ and $v$ respectively.

\subsection{The South Australian Sea case}

\subsubsection{Control run}

Before conducting data assimilation for the real case, a model capable of producing reasonable climatology is required. Fig. 5 displays the comparison between the simulated SST and the OISST dataset. Both the mean and the variability of the model results and observation are in good agreement. The model reproduces the warm pattern with little variability along the coast, which is a main feature of the north boundary currents. The model also captures the high variability in the shallow water region of the Spencer Gulf and the Gulf St Vincent. However, the model variability in the central western part is greater than OISST, which indicates a stronger meandering of the north boundary currents than observed.

An EOF analysis is carried out to extract the main variability of SLA. The first 2 EOFs of the original SLA (not shown) in ROMS and AVISO are similar. They represent the seasonal cycle and explain $70 \%-80 \%$ of the variability. Fig. 6 depicts the first 2 EOFs of the deseasonalised SLA from ROMS and AVISO. The first EOF represents an annual cycle overlapped 
on a low-frequency oscillation near the coastline. ROMS shows a similar spatiotemporal pattern with AVISO. The second EOF of AVISO represents high-frequency eddy events in the west of the domain while for ROMS there is a larger feature in the middle of the domain. The model reproduces the seasonal cycle and low-frequency feature, but the eddy activity is not captured well.

In the 7 year mean of simulated surface currents, the strong eastward north boundary currents in winter and weak westward currents in the summer are also reproduced (not shown), as seen in the observed climatology (e.g. Middleton and Bye, 2007, in their Fig. 2).

\subsubsection{Standard data assimilation}

SST and SSH are assimilated in these experiments, together and separately. The results suggest that assimilating SST and SSH improves these two variables, and assimilating SSH also produces a better subsurface temperature profile. However, unlike in some other studies (e.g. Hoteit et al., 2013; Kurapov et al., 2011), SSH assimilation does not generate a more accurate SST distribution. When both SST and SSH are assimilated at the same time, the correction to both SST and SSH field is very similar to that of the SST assimilation only. We validate the performance of data assimilation by comparing the domain-averaged RMSE of SST and SSH for different experiments. The error of surface and subsurface temperature is calculated against the OISST dataset and Argo observations. Compared to the control run $(\operatorname{ExpA})$, assimilating SST alone $(\operatorname{ExpC})$ reduces the SST error by $58 \%$ from $0.86^{\circ} \mathrm{C}$ to $0.36^{\circ} \mathrm{C}$ (Fig. $7(\mathrm{~A})$ and Table 3)," and the error decreases from above $0.7^{\circ} \mathrm{C}$ in most of the domain to around $0.3^{\circ} \mathrm{C}$. The 5 -day forecast is also much better $\left(\mathrm{RMSE}=0.55^{\circ} \mathrm{C}\right)$ than the control run (Fig. $7(\mathrm{~B})$ ). The difference of RMSE between assimilating SST with (ExpD) and without SSH is marginal (RMSE for posterior state is $0.37^{\circ} \mathrm{C}$ ), indicating that the process of SST adjustment is mainly determined by the assimilation of SST. The SST observations are more numerous $\left({ }^{\sim} 3200 /\right.$ day $)$ and have a bigger spatial coverage than the SSH observations ( $\sim 400 /$ day). In addition, the error of SST mainly provides information about the surface heat flux which has little effect on SSH. A finer tuning of SSH/SST combination may improve the results. On the other hand, when assimilating SSH (ExpB), the RMSE is quite similar to the control run and the spatial pattern is also similar. The comparison with Argo temperature and salinity profiles (Fig. 8, Table 3) shows that, although the subsurface variables are not assimilated, a better 
distribution is reproduced. For instance, assimilating $\mathrm{SSH}$ alone reduces the RMSE of temperature and salinity by $12 \%\left(0.14^{\circ} \mathrm{C}\right)$ and $10 \%(0.02 \mathrm{PSU})$, respectively, in the upper $300 \mathrm{~m}$. In ExpC (assimilating SST alone), the error of temperature reduces by $10 \%\left(0.12^{\circ} \mathrm{C}\right)$ in the upper $300 \mathrm{~m}$ but increases by $7 \%\left(0.07^{\circ} \mathrm{C}\right)$ in $300-700 \mathrm{~m}$, indicating the simulation of ocean circulation is degenerated. ExpD also showss that assimilating SST increases the error, especially under $300 \mathrm{~m}$. The results for salinity are similar.

For SSH the largest improvement is achieved by assimilating SSH only (ExpB). The error against AVISO data in posterior state reduces by $26 \%$ from $8.9 \mathrm{~cm}$ to $6.6 \mathrm{~cm}$ (Fig. 9(A)). In the control run, the error is approximately 8 $\mathrm{cm}$ in most of the region, but in the southern part, it is about $13 \mathrm{~cm}$. When $\mathrm{SSH}$ is assimilated, the error in the whole domain is low $(5 \mathrm{~cm})$ and uniform. In the 5-day forecast, ExpB still produces a lower error $(7.0 \mathrm{~cm})$ than the control run showing that the signal in SSH assimilation can last at least 5 days. When SST is assimilated alone, the error in the analysis $(9.6 \mathrm{~cm})$ is actually higher than in the control run, especially in the autumn and winter seasons. When both SSH and SST are assimilated, the error in the analysis $(8.0 \mathrm{~cm})$ is lower than the SST alone assimilation, but is still higher than the control run during the last 80 days.

\subsubsection{Balanced data assimilation}

The effect of the balance operator is tested in two experiments by assimilating SSH alone (ExpE) and with SST (ExpF). When only SSH is assimilated, the major constraint is the geostrophic balance. If SST is also assimilated, the hydrostatic balance also provides some correction. Compared with the original algorithm, the balance operator improves the SSH and temperature estimation. As shown in Fig 7 and 9, the RMSE of both SST and SSH in ExpE ( $\mathrm{SSH}$ assimilation with the balance operator) is lower during most of the period. Although the difference of average error is marginal in ExpB and $\operatorname{ExpE}$ (6.57 and $6.50 \mathrm{~cm}$ for SSH; 0.85 and $0.81^{\circ} \mathrm{C}$ for SST, respectively), the improvement is more significant during some periods and can be as high as $0.2{ }^{\circ} \mathrm{C}$ and $1 \mathrm{~cm}$. Particularly, the SSH forecast error with the balance operator is smaller by 1-3 cm than the unbalanced approach, suggesting that a posterior state with compatible SSH and velocity field is necessary for a better SSH forecast.

As for the subsurface, assimilating SSH with the balance operator is an optimal way to improve the subsurface temperature profile. For example, compared to ExpB, the improvement of temperature in ExpE is as high as 
$0.12{ }^{\circ} \mathrm{C}$ for the upper $300 \mathrm{~m}$. On the other hand, if SST is assimilated, even with the balance operator (ExpF), the SSH error is higher than ExpE. The error of salinity shows similar trend.

A major challenge facing ocean data assimilation and forecast is the simulation of currents. The results demonstrate the benefit from the geostrophic balance. Assimilating SSH with the balance operator produces the most realistic surface currents while SST assimilation does not improve the currents. The model surface currents are compared against OSCAR $1 / 3^{\circ} 5$-day mean ocean currents due to the spatial and temporal coverage (Fig. 10). Without data assimilation, the half-year mean RMSE of the currents components $u$ and $v$ in the control run (ExpA) is $2.03 \mathrm{~cm} / \mathrm{s}$ and $0.86 \mathrm{~cm} / \mathrm{s}$ respectively. By using the original EAKF, the error of $u$ and $v$ decreases by $32 \%$ to $1.39 \mathrm{~cm} / \mathrm{s}$ and $12 \%$ to $0.76 \mathrm{~cm} / \mathrm{s}$. When the balance operator is used, the error of $u$ and $v$ decreases by a further $27 \%$ to $1.02 \mathrm{~cm} / \mathrm{s}$ and $23 \%$ to $0.59 \mathrm{~cm} / \mathrm{s}$. The performance of the balanced EAKF is thus the best among all three experiments and reduces the error by $40 \%$ to $50 \%$ compared to the control run. A comparison with the drifter derived surface currents gives similar results (Table. 3), although the error is much higher than for the domain average.

The spatial pattern of surface currents (Fig. 11) also demonstrates the advantage of the balance operator for the currents simulation. In the control run the model is able to capture the eastward coastal currents but the currents are too strong and reach the east coast of the Great Australian Bight. In addition, an anticyclonic eddy is observed in the middle of the domain $\left(127^{\circ} \mathrm{E}^{\sim} 130^{\circ} \mathrm{E}, 34^{\circ} \mathrm{S}^{\sim} 37^{\circ} \mathrm{S}\right)$ in the OSCAR dataset. The control run does not produce this eddy and the speed error is around $4 \mathrm{~cm} / \mathrm{s}$ in this region. When SSH is assimilated, even when the balance operator is not used, the over strong north boundary currents is weaker and more realistic. The assimilation also reproduces the anticyclonic eddy, and the assimilation with the balance operator (speed error $\sim 2 \mathrm{~cm} / \mathrm{s}$ ) is more realistic than that without (speed error $\sim 2.5 \mathrm{~cm} / \mathrm{s}$ ).

\subsection{A case study with strong wind forcing}

From 26 March 2007 to 27 March 2007, a storm passed the region, with a mean wind stress of $0.22 \mathrm{~Pa}$ and a maximum of $0.31 \mathrm{~Pa}$. This process is of particular importance because the data assimilation cycle starts on 27 March 2007. Therefore the prior state is strongly unbalanced because the storm creates strong ageostrophic currents and the posterior state is also unbalanced. 
Fig. 12 depicts the ageostrophic currents in SSH assimilations with and without balance operator in a subdomain significantly impacted by this storm $\left(126^{\circ} \mathrm{E}^{\sim} 132^{\circ} \mathrm{E}, 34^{\circ} \mathrm{S}^{\sim} 37^{\circ} \mathrm{S}\right)$. The ageostrophic currents are stronger without balance operator $(25.1 \mathrm{~cm} / \mathrm{s}$ and $20.8 \mathrm{~cm} / \mathrm{s}$ in ExpB and ExpE respectively). In the prior state (5-day forecast) on 01 April 2007, the ageostrophic currents reduce in both experiments but remain stronger in the unbalanced experiment $(13.7 \mathrm{~cm} / \mathrm{s}$ and $10.3 \mathrm{~cm} / \mathrm{s})$. The comparison between simulated SSH and the AVISO observation also shows that the balanced experiment is more realistic (figure not shown).

When compared with the OSCAR dataset, the domain-averaged error of the 5-day mean surface currents during this period with the balance operator $(1.4 \mathrm{~cm} / \mathrm{s}$ and $0.7 \mathrm{~cm} / \mathrm{s}$ for $u$ and $v$ respectively) is much smaller than that without balance operator $(2.1 \mathrm{~cm} / \mathrm{s}$ and $1.1 \mathrm{~cm} / \mathrm{s}$ for $u$ and $v$ respectively). Daily differences between these two experiments are up to $3.2 \mathrm{~cm} / \mathrm{s}$. However, the daily observations are not available to verify which experiment is better. This case study suggests that when the wind stress is large (e.g., greater than $0.2 \mathrm{~Pa}$ ) and hence the ageostrophic currents are strong, the balance operator is essential for a better estimation of the surface currents.

\section{Discussion}

In this study, we assimilate surface observations in both an idealised and a real cases and reduce the imbalance caused by the data assimilation process. Numerical models are designed to be physically balanced so the forecast of each ensemble should be equilibrated. However the combination of observation and numerical model is not balanced so data assimilation introduces imbalance and spurious waves into the dynamical systems (e.g. Greybush et al., 2011; Kepert, 2009; Lorenc, 2003; Neef et al., 2006). Theoretically, the numerical model is able to remove the imbalance within a certain period but the effect of unbalanced waves has been shown to be important in this paper and other studies (e.g. Kepert, 2009; Neef et al., 2006). Several methods have been proposed to eliminate such waves. For example, by using a low-order idealised model, Neef et al. (2006) have demonstrated that the waves can be removed by increasing the ensemble size and decreasing the assimilation window, but it is usually difficult to do so in the high-dimensional GCMs.

Due to the small ensemble size, the covariance used in EnKFs is usually insufficient to represent the true relationship between state variables. Estimates of the background error covariance between substantially distant grid 
points are often exaggerated when using a small ensemble size (Houtekamer and Mitchell, 1998). Therefore a localisation procedure is necessary. However, localisation also causes spurious waves (e.g. Greybush et al., 2011; Lorenc, 2003) and thus is a main disadvantage of EnKFs.

Following Weaver et al. (2005), three physical balance constraints (temperaturesalinity, hydrostatic and geostrophic balance) are used in this paper to reduce these spurious waves. We use an idealised shallow water model to reveal how the geostrophic balance operator enhances the data assimilation by removing the initial spurious ageostrophic waves. In this idealised model, the increment is strongly unbalanced (Fig. 2) without the balance operator and the spurious waves persist more than 24 hours. The unrealistic ageostrophic currents reduce the performance of data assimilation and therefore a balance operator is needed.

In the real case, the balance operator is also valuable in the estimation of ocean currents. Fig. 13 displays an example of the ensemble correlation between SST, SSH and surface and subsurface zonal ocean currents from a prior ensemble in the SSH only assimilation (ExpB). The correlation of surface variables with ocean currents is defined as,

$$
\begin{aligned}
& C_{H U V}=\sqrt{\frac{1}{2}\left(\operatorname{Corr}(S S H, U)^{2}+\operatorname{Corr}(S S H, V)^{2}\right)} . \\
& C_{T U V}=\sqrt{\frac{1}{2}\left(\operatorname{Corr}(S S T, U)^{2}+\operatorname{Corr}(S S T, V)^{2}\right)} .
\end{aligned}
$$

It is evident that in most of the region the correlation between surface observed variables and ocean currents is noisy and weak (less than 0.5 in most of the region). For the deeper currents, the correlation is slightly stronger, especially in the southern part. Further analysis (figure not shown) reveals that in the eastern part the currents are dominated by wind stress and the southern part features with stronger SSH variability. This could explain why EAKF and Ensemble Optimal Interpolation (EnOI) show good results in the Gulf of Mexico (Hoteit et al., 2013; Counillon and Bertino, 2009) where the SSH variability is dominated by the loop current and the correlation between SSH and surface currents is high (0̃.7 - 0.8, (Counillon and Bertino, 2009)). However, in the Southern Australian Sea, the SSH variability is not constant and shows lower correlation with ocean currents. Thus EAKF gives worse currents result when only SSH is assimilated. Therefore the physical constraint is particularly important in this region. 
The advantages of the balance operator have been shown in both an idealised shallow water model and the ROMS real case, in which the error of temperature, salinity, SSH and velocities reduces. Especially for the subsurface temperature and salinity, when SSH is assimilated with the balance operator, the simulated error reduces dramatically in each layer. This indicates a better subsurface ocean circulation is produced. While SST is also assimilated, the error increases. This may be because the SST information in this region does not reflect the mesoscale ocean dynamics, which also seen in the unbalanced experiments. Compared with other approaches (e.g., using the streamfunction-velocity potential covariance, Kepert, 2009), the balance operator is straightforward and easy to compute and implement. In this work, the balanced part of sea surface height is approximated by integrating the density from a reference level. However, in regions where the bathymetry is complicated, that may be questionable. Another potential challenge of implementing the balance operator is that the mixed layer depth varies in time and space, but here we assign a constant value. Nevertheless, we anticipate this to be a minor correction.

\section{Conclusion}

An EnKF based ocean data assimilation system has been developed and applied to the South Australian Sea in this paper. This system applies the Ensemble Adjustment Kalman Filter (EAKF) in the Data Assimilation Research Testbed (DART) to the Regional Ocean Modeling System (ROMS). Spurious waves are created in the data assimilation process due to the localisation and multivariate update scheme. We add a physical balance operator to this system to eliminate these spurious waves. The effect of the balance operator is demonstrated in a two dimensional shallow water model for different localisation scale. A larger localisation shows advantages over the smaller one. For both localisation scales, the balance operator decreases the error of sea surface height and velocities. It is also shown that the benefit of balance operator increases as the amplitude of SSH and wind stress increase.

SST and SSH are assimilated separately in a $10 \mathrm{~km}$ resolution ROMS model of the South Australian Sea, the error of SST and SSH reduces in the analysis. However, assimilating SST deteriorates the overall estimation of SSH, especially in the winter season. On the other hand, in the SSH assimilation experiment, the distribution of SST is similar to the control run. The assimilation of both SST and SSH is similar to just SST because 
the number of SST observations is much higher than SSH. Assimilating SSH also improves the estimation of surface ocean currents. The balance operator is then used in the SSH only and SSH and SST assimilation experiments. The estimations of both SSH and temperature are improved, especially for the forecast, indicating a balanced posterior state is important. The balance operator is important in the estimation of ocean currents, assimilating SSH with the balance operator produces ocean currents the most comparable with OSCAR dataset. The error of $u$ and $v$ is reduced by $27 \%$ and $23 \%$ compared with the original data assimilation. The comparison with drifter derived surface currents shows similar results. The error of temperature profiles against Argo data suggests assimilating SSH with balance operator produces the most realistic subsurface temperature and salinity. A case study with a storm affecting this region shows that under high wind forcing condition the balance operator reduces the ageostrophic currents significantly in both analysis and forecast. The results in all experiments performed in this paper suggest that the balance operator may be useful to implement generally in ocean data assimilation systems.

\section{Acknowledgment}

This paper is sponsored by the Chinese Scholarship Council (CSC) - Imperial College London scholarship and BP Environmental Technology program. We thank Dr. Ibrahim Hoteit, Professor Andrew Moore and the DART team for their suggestions and comments.

\section{References}

Anderson, J., Hoar, T., Raeder, K., Liu, H., Collins, N., Torn, R., Avellano, A., 2009. The data assimilation research testbed a community facility. Bulletin of the American Meteorological Society 90 (9), 1283-1296.

Anderson, J. L., 2001. An Ensemble Adjustment Kalman Filter for Data Assimilation. Monthly Weather Review 129, 2884-2903.

Anderson, J. L., 2003. A Local Least Squares Framework for Ensemble Filtering. Monthly Weather Review 131 (4), 634-642.

Anderson, J. L., 2007a. An adaptive covariance inflation error correction algorithm for ensemble filters. Tellus A 59 (2), 210-224.

URL http://tellusa.net/index.php/tellusa/article/view/14925 
Anderson, J. L., 2007b. Exploring the need for localization in ensemble data assimilation using a hierarchical ensemble filter. Physica D: Nonlinear Phenomena 230 (1-2), 99-111.

URL http://linkinghub.elsevier.com/retrieve/pii/ S0167278906002168

Balmaseda, M. A., Mogensen, K., Weaver, A. T., 2013. Evaluation of the ECMWF ocean reanalysis system ORAS4. Quarterly Journal of the Royal Meteorological Society 139 (674), 1132-1161.

Blayo, E., Bocquet, M., Cosme, E., Cugliandolo, L. F., 2014. Advanced Data Assimilation for Geosciences: Lecture Notes of the Les Houches School of Physics: Special Issue, June 2012. Oxford University Press. URL https://books . google. com/books?id=RSXSBAAAQBAJ $\{\backslash \&\}$ pgis=1

Bonjean, F., Lagerloef, G. S. E., 2002. Diagnostic model and analysis of the surface currents in the tropical Pacific Ocean. Journal of Physical Oceanography 32 (10), 2938-2954. URL <GotoISI> ://000178078800015

Cohn, S. E., Parrish, D. F., 1991. The behavior of forecast error covariances for a Kalman filter in two dimensions.

Counillon, F., Bertino, L., 2009. Ensemble Optimal Interpolation: Multivariate properties in the Gulf of Mexico. Tellus, Series A: Dynamic Meteorology and Oceanography 61 (2), 296-308.

Dohan, K., Maximenko, N., 2010. Monitoring Ocean Currents with Satellite Sensors. Oceanography 23 (4), 94-103.

Emerick, A., Reynolds, A., 3 2011. Combining sensitivities and prior information for covariance localization in the ensemble Kalman filter for petroleum reservoir applications. Computational Geosciences 15 (2), 251-269. URL http://link. springer.com/10.1007/s10596-010-9198-y

Evensen, G., 1994. Sequential data assimilation with a nonlinear quasigeostrophic model using Monte Carlo methods to forecast error statistics. Journal of Geophysical Research 99 (C5), 10143.

URL http://doi.wiley.com/10.1029/94JC00572 
Evensen, G., 2003. The Ensemble Kalman Filter: Theoretical formulation and practical implementation. Ocean Dynamics 53 (4), 343-367.

Evensen, G., 2009. Data Assimilation. Springer Berlin Heidelberg, Berlin, Heidelberg.

URL http://link.springer.com/10.1007/978-3-642-03711-5

Evensen, G., van Leeuwen, P. J., 1996. Assimilation of Geosat Altimeter Data for the Agulhas Current Using the Ensemble Kalman Filter with a Quasigeostrophic Model. Monthly Weather Review 124 (1), 85-96.

Gaspari, G., Cohn, S. E., 1 1999. Construction of correlation functions in two and three dimensions. Quarterly Journal of the Royal Meteorological Society 125 (554), 723-757.

URL http://doi.wiley.com/10.1002/qj . 49712555417

Greybush, S. J., Kalnay, E., Miyoshi, T., Ide, K., Hunt, B. R., 22011. Balance and Ensemble Kalman Filter Localization Techniques. Monthly Weather Review 139 (2), 511-522. URL http://journals.ametsoc.org/doi/abs/10.1175/2010MWR3328. 1

Haidvogel, D. B., Arango, H., Budgell, W. P., Cornuelle, B. D., Curchitser, E., Di Lorenzo, E., Fennel, K., Geyer, W. R., Hermann, a. J., Lanerolle, L., Levin, J., McWilliams, J. C., Miller, a. J., Moore, a. M., Powell, T. M., Shchepetkin, a. F., Sherwood, C. R., Signell, R. P., Warner, J. C., Wilkin, J., 2008. Ocean forecasting in terrain-following coordinates: Formulation and skill assessment of the Regional Ocean Modeling System. Journal of Computational Physics 227 (7), 3595-3624.

Haidvogel, D. B., Arango, H. G., Hedstrom, K., Beckmann, A., MalanotteRizzoli, P., Shchepetkin, A. F., 2000. Model evaluation experiments in the North Atlantic Basin: Simulations in nonlinear terrain-following coordinates. Dynamics of Atmospheres and Oceans 32 (3-4), 239-281.

Hoteit, I., Hoar, T., Gopalakrishnan, G., Collins, N., Anderson, J., Cornuelle, B., Köhl, A., Heimbach, P., 2013. A MITgcm/DART ensemble analysis and prediction system with application to the Gulf of Mexico. Dynamics of Atmospheres and Oceans 63, 1-23.

URL http://dx.doi.org/10.1016/j.dynatmoce.2013.03.002 
Hoteit, I., Pham, D.-T., Triantafyllou, G., Korres, G., 2008. A New Approximate Solution of the Optimal Nonlinear Filter for Data Assimilation in Meteorology and Oceanography. Monthly Weather Review 136 (1), $317-$ 334 .

Houtekamer, P. L., Mitchell, H. L., 1998. Data assimilation using an ensemble Kalman filter technique. Monthly Weather Review 126 (3), 796-811.

URL http://journals.ametsoc org/doi/abs/10. 1175/1520-0493(1998) 126<0796:DAUAEK>2 . 0.CO; $2\{\backslash$ textbackslash $\}$ n<GotoISI $>$ : //000072409000016

Houtekamer, P. L., Mitchell, H. L., 2001. A Sequential Ensemble Kalman Filter for Atmospheric Data Assimilation. Monthly Weather Review 129 (1), $123-137$.

Jackett, D. R., Mcdougall, T. J., 1995. Minimal Adjustment of Hydrographic Profiles to Achieve Static Stability.

URL http://journals.ametsoc.org.ezproxy.otago.ac.nz/doi/abs/ 10.1175/1520-0426(1995)012\{\\%\}3C0381:MAOHPT $\{\backslash \%\} 3 E 2.0 . C 0 ; 2$

Jacobs, G. A., Bartels, B. P., Bogucki, D. J., Beron-Vera, F. J., Chen, S. S., Coelho, E. F., Curcic, M., Griffa, A., Gough, M., Haus, B. K., Haza, A. C., Helber, R. W., Hogan, P. J., Huntley, H. S., Iskandarani, M., Judt, F., Kirwan, A. D., Laxague, N., Valle-Levinson, A., Lipphardt, B. L., J. Mariano, A., Ngodock, H. E., Novelli, G., Olascoaga, M. J., Özgökmen, T. M., Poje, A. C., Reniers, A. J. H. M., Rowley, C. D., Ryan, E. H., Smith, S. R., Spence, P. L., Thoppil, P. G., Wei, M., 2014. Data assimilation considerations for improved ocean predictability during the Gulf of Mexico Grand Lagrangian Deployment (GLAD). Ocean Modelling 83, 98-117. URL http://dx.doi.org/10.1016/j.ocemod.2014.09.003

Kalman, R. E., 1960. A New Approach to Linear Filtering and Prediction Problems. Transactions of the ASME-Journal of Basic Engineering 82 (Series D), 35-45.

URL http://fluidsengineering.asmedigitalcollection.asme.org/ article.aspx?articleid=1430402

Karspeck, A. R., Yeager, S., Danabasoglu, G., Hoar, T., Collins, N., Raeder, K., Anderson, J., Tribbia, J., 10 2013. An Ensemble Adjustment Kalman 
Filter for the CCSM4 Ocean Component. Journal of Climate 26 (19), 7392-7413.

URL http://journals.ametsoc.org/doi/abs/10.1175/ JCLI-D-12-00402.1

Kepert, J. D., 7 2009. Covariance localisation and balance in an Ensemble Kalman Filter. Quarterly Journal of the Royal Meteorological Society 135 (642), 1157-1176.

URL http://onlinelibrary.wiley.com/doi/10.1002/qj.71/ abstracthttp://doi.wiley.com/10.1002/qj.443

Kurapov, A. L., Foley, D., Strub, P. T., Egbert, G. D., Allen, J. S., 2011. Variational assimilation of satellite observations in a coastal ocean model off Oregon. Journal of Geophysical Research: Oceans 116 (5), 1-19.

Lahoz, W. a., Schneider, P., 2014. Data assimilation: making sense of Earth Observation. Frontiers in Environmental Science 2 (May), 1-28.

URL http://www.frontiersin.org/Atmospheric\{\_\}Science/10. 3389/fenvs. 2014.00016/abstract

Li, Z., Chao, Y., McWilliams, J. C., Ide, K., 2008. A Three-Dimensional Variational Data Assimilation Scheme for the Regional Ocean Modeling System. Journal of Atmospheric and Oceanic Technology 25 (11), 20742090 .

URL http://journals.ametsoc.org/doi/abs/10.1175/ 2008JTECH0594.1

Lorenc, A. C., 2003. The potential of the ensemble Kalman filter for NWPa comparison with 4D-Var. Quarterly Journal of the Royal Meteorological Society 129 (595), 31833203.

URL http://onlinelibrary.wiley.com/doi/10.1256/qj.02.132/ abstract $\{\backslash$ textbackslash\}nhttp://onlinelibrary.wiley.com/ store/10.1256/qj.02.132/asset/200312959502\{\_\}ftp.pdf?v=1\{\\& \}$t=h j 1 \mathrm{ka} 6 \mathrm{so}\{\backslash \&\} \mathrm{s}=\mathrm{e} 564633232801960 \mathrm{a} 20 \mathrm{ad} 6 \mathrm{f} 4238 \mathrm{bbc510c6bf0c2}$

Lumpkin, R., Pazos, M., 2007. Measuring surface currents with Surface Velocity Program drifters: the instrument, its data, and some recent results. In: Griffa, A., Kirwan, Jr., A. D., Mariano, A. J., Özgökmen, T., Rossby, H. T. (Eds.), Lagrangian Analysis and Prediction of Coastal and Ocean Dynamics. Cambridge University Press, Ch. 2. 
Lyard, F., Lefevre, F., Letellier, T., Francis, O., 12 2006. Modelling the global ocean tides: modern insights from FES2004. Ocean Dynamics 56 (5-6), 394-415.

URL http://link.springer.com/10.1007/s10236-006-0086-x

Metzger, E., Smedstad, O. M., Thoppil, P. G., Hurlburt, H. E., Cummings, J. A., Wallcraft, A. J., Zamudio, L., Franklin, D. S., Posey, P. G., Phelps, M. W., Hogan, P. J., Bub, F. L., Dehaan, C. J., 2014. US Navy Operational Global Ocean and Arctic Ice Prediction Systems. Oceanography 27 (3), 3243.

URL http://dx.doi.org/10.5670/oceanog.2011.80.

Middleton, J. F., Bye, J. a. T., 2007. A review of the shelf-slope circulation along Australia's southern shelves: Cape Leeuwin to Portland. Progress in Oceanography 75 (1), 1-41.

Mitchell, H. L., Houtekamer, P. L., Pellerin, G., 2002. Ensemble Size, Balance, and Model-Error Representation in an Ensemble Kalman Filter*. Monthly Weather Review 130 (11), 2791-2808.

Moore, A. M., Arango, H. G., Broquet, G., Edwards, C., Veneziani, M., Powell, B., Foley, D., Doyle, J. D., Costa, D., Robinson, P., 2011a. The Regional Ocean Modeling System (ROMS) 4-dimensional variational data assimilation systems. Part II - Performance and application to the California Current System. Progress in Oceanography 91 (1), 50-73.

URL http://dx.doi.org/10.1016/j.pocean.2011.05.003

Moore, A. M., Arango, H. G., Broquet, G., Edwards, C., Veneziani, M., Powell, B., Foley, D., Doyle, J. D., Costa, D., Robinson, P., 2011b. The Regional Ocean Modeling System (ROMS) 4-dimensional variational data assimilation systems. Part III - Observation impact and observation sensitivity in the California Current System. Progress in Oceanography 91 (1), 74-94.

URL http://dx.doi.org/10.1016/j.pocean.2011.05.005

Moore, A. M., Arango, H. G., Broquet, G., Powell, B. S., Weaver, A. T., Zavala-Garay, J., 2011c. The Regional Ocean Modeling System (ROMS) 4dimensional variational data assimilation systems. Part I - System overview and formulation. Progress in Oceanography 91 (1), 34-49.

URL http://dx.doi.org/10.1016/j.pocean. 2011.05.004 
Moore, A. M., Edwards, C. A., Fiechter, J., Drake, P., Neveu, E., Arango, H. G., Gürol, S., Weaver, A. T., 2013. Data Assimilation for Atmospheric, Oceanic and Hydrologic Applications (Vol. II). Springer Berlin Heidelberg, Berlin, Heidelberg, Ch. A 4D-Var A, pp. 345-366.

URL http://dx.doi.org/10.1007/978-3-642-35088-7\{\_\}14

Neef, L. J., Polavarapu, S. M., Shepherd, T. G., 7 2006. Four-Dimensional Data Assimilation and Balanced Dynamics. Journal of the Atmospheric Sciences 63 (7), 1840-1858.

URL http://journals.ametsoc.org/doi/abs/10.1175/JAS3714.1

Oke, P. R., Sakov, P., Cahill, M. L., Dunn, J. R., Fiedler, R., Griffin, D. A., Mansbridge, J. V., Ridgway, K. R., Schiller, A., 2013. Towards a dynamically balanced eddy-resolving ocean reanalysis: BRAN3. Ocean Modelling $67,52-70$.

URL http://dx.doi.org/10.1016/j.ocemod.2013.03.008

Pham, D. T., 2001. Stochastic methods for sequential data assimilation in strongly nonlinear systems. Monthly Weather Review 129 (5), 1194-1207. URL //000168510700016

Reynolds, R. W., Smith, T. M., Liu, C., Chelton, D. B., Casey, K. S., Schlax, M. G., 11 2007. Daily High-Resolution-Blended Analyses for Sea Surface Temperature. Journal of Climate 20 (22), 5473-5496. URL http://journals.ametsoc.org/doi/abs/10.1175/ 2007 JCLI1824. 1

Saha, S., Moorthi, S., Pan, H. L., Wu, X., Wang, J., Nadiga, S., Tripp, P., Kistler, R., Woollen, J., Behringer, D., Liu, H., Stokes, D., Grumbine, R., Gayno, G., Wang, J., Hou, Y. T., Chuang, H. Y., Juang, H. M. H., Sela, J., Iredell, M., Treadon, R., Kleist, D., Van Delst, P., Keyser, D., Derber, J., Ek, M., Meng, J., Wei, H., Yang, R., Lord, S., Van Den Dool, H., Kumar, A., Wang, W., Long, C., Chelliah, M., Xue, Y., Huang, B., Schemm, J. K., Ebisuzaki, W., Lin, R., Xie, P., Chen, M., Zhou, S., Higgins, W., Zou, C. Z., Liu, Q., Chen, Y., Han, Y., Cucurull, L., Reynolds, R. W., Rutledge, G., Goldberg, M., 2010. The NCEP climate forecast system reanalysis. Bulletin of the American Meteorological Society 91 (8), 10151057. 
Seo, G.-H., Choi, B.-J., Cho, Y.-K., Kim, Y. H., Kim, S., 12 2010. Assimilation of sea surface temperature in the Northwest Pacific Ocean and its marginal seas using the ensemble Kalman filter. Ocean Science Journal 45 (4), 225-242.

URL http://www.springerlink.com/index/10.1007/ s12601-010-0021-4http://link.springer.com/10.1007/ s12601-010-0021-4

Shchepetkin, A. F., McWilliams, J. C., 2005. The regional oceanic modeling system (ROMS): A split-explicit, free-surface, topography-followingcoordinate oceanic model. Ocean Modelling 9 (4), 347-404.

Shchepetkin, A. F., McWilliams, J. C., 2009. Correction and commentary for "Ocean forecasting in terrain-following coordinates: Formulation and skill assessment of the regional ocean modeling system" by Haidvogel et al., J. Comp. Phys. 227, pp. 3595-3624. Journal of Computational Physics 228 (24), 8985-9000.

URL http://dx.doi.org/10.1016/j.jcp.2009.09.002

Smith, W. H., 1997. Global Sea Floor Topography from Satellite Altimetry and Ship Depth Soundings. Science 277 (5334), 1956-1962.

Song, H., Miller, A. J., McClatchie, S., Weber, E. D., Nieto, K. M., Checkley, D. M., 2012. Application of a data-assimilation model to variability of Pacific sardine spawning and survivor habitats with ENSO in the California Current System. Journal of Geophysical Research: Oceans 117 (3), 1-15.

Tippett, M. K., Anderson, J. L., Bishop, C. H., Hamill, T. M., Whitaker, J. S., 7 2003. Ensemble Square Root Filters*. Monthly Weather Review 131 (7), 1485-1490.

URL http://journals.ametsoc.org/doi/abs/10.1175/ 1520-0493(2003) 131\{\\%\}3C1485: ESRF $\{\backslash \%\} 3 E 2.0 . C 0 ; 2$ http:

//journals.ametsoc.org/doi/abs/10.1175/1520-0493\{\\%\}282003\{\\% \}29131\{\\%\}3C1485\{\\%\}3AESRF $\{\backslash \%\} 3 E 2.0 . \mathrm{CO}\{\backslash \%\} 3 \mathrm{~B} 2$

Vorosmarty, C. J., Fekete, B., Tucker, B., 1998. Global River Discharge, 1807-1991, Version 1.1 (RivDIS).

URL http://daac.ornl.gov/cgi-bin/dsviewer.pl?ds $\{\backslash$ \}id= 199http://www.daac.ornl.gov 
Weaver, A. T., Deltel, C., Machu, E., Ricci, S., Daget, N., 2005. A multivariate balance operator for variational ocean data assimilation. Quarterly Journal of the Royal Meteorological Society 131 (613), 3605-3625.

URL http://doi.wiley.com/10.1256/qj.05.119

White, R. H., Toumi, R., 2014. River flow and ocean temperatures: The Congo River. Journal of Geophysical Research: Oceans 119 (4), 25012517.

Wikle, C. K., Berliner, L. M., 2007. A Bayesian tutorial for data assimilation. Physica D: Nonlinear Phenomena 230 (1-2), 1-16.

Wilkin, J. L., Arango, H. G., Haidvogel, D. B., Lichtenwalner, C. S., Glenn, S. M., Hedström, K. S., 2005. A regional ocean modeling system for the Long-term Ecosystem Observatory. Journal of Geophysical Research: Oceans 110 (6), 1-13. 


\begin{tabular}{|c|c|c|c|}
\hline Experiment set & $\eta_{0}(\mathrm{~cm})$ & $\tau_{0}(\mathrm{~Pa})$ & localisation scale $(\mathrm{km})$ \\
\hline A (fixed $\tau_{0}$ amplitude) & $5,10,20,30,40,50$ & 0.1 & 60,100 \\
\hline B (fixed $\eta_{0}$ amplitude) & 10 & $0.05,0.1,0.2,0.3,0.4,0.5$ & 60,100 \\
\hline
\end{tabular}

Table 1: Experiment design for the shallow water model 


\begin{tabular}{|c|c|c|}
\hline Experiment & Assimilated variables & Balance operator \\
\hline ExpA (control run) & None & No \\
\hline ExpB & SSH & No \\
\hline ExpC & SST & No \\
\hline ExpD & SSH and SST & No \\
\hline ExpE & SSH & Yes \\
\hline ExpF & SSH and SST & Yes \\
\hline
\end{tabular}

Table 2: Experiment design for the ROMS real case 


\begin{tabular}{|c|c|c|c|c|c|c|}
\hline & ExpA & ExpB & ExpC & ExpD & ExpE & ExpF \\
\hline$S S H$ & 8.87 & 6.57 & 9.55 & 7.98 & 6.50 & 7.28 \\
\hline$S S T$ & 0.86 & 0.85 & 0.36 & 0.37 & 0.81 & 0.33 \\
\hline$u$ & 25.80 & 20.73 & 23.79 & 23.81 & 19.52 & 21.40 \\
\hline$v$ & 21.32 & 19.23 & 23.13 & 22.35 & 18.19 & 20.73 \\
\hline$t(100-300 \mathrm{~m})$ & 1.18 & 1.04 & 1.06 & 0.94 & 0.92 & 0.99 \\
\hline$t(300-700 \mathrm{~m})$ & 1.15 & 1.13 & 1.22 & 1.14 & 1.06 & 1.12 \\
\hline$t(700-1500 \mathrm{~m})$ & 0.69 & 0.51 & 0.61 & 0.61 & 0.59 & 0.57 \\
\hline$s(100-300 \mathrm{~m})$ & 0.20 & 0.18 & 0.21 & 0.19 & 0.18 & 0.21 \\
\hline$s(300-700 \mathrm{~m})$ & 0.09 & 0.07 & 0.10 & 0.05 & 0.06 & 0.08 \\
\hline$s(700-1500 \mathrm{~m})$ & 0.13 & 0.12 & 0.14 & 0.12 & 0.12 & 0.13 \\
\hline
\end{tabular}

Table 3: The RMSE of SSH, SST surface currents and subsurface temperature and salinity compared with AVISO, OISST, drifter and ARGO data. The units are $\mathrm{cm},{ }^{\circ} \mathrm{C}, \mathrm{cm} / \mathrm{s},{ }^{\circ} \mathrm{C}$ and PSU respectively. 


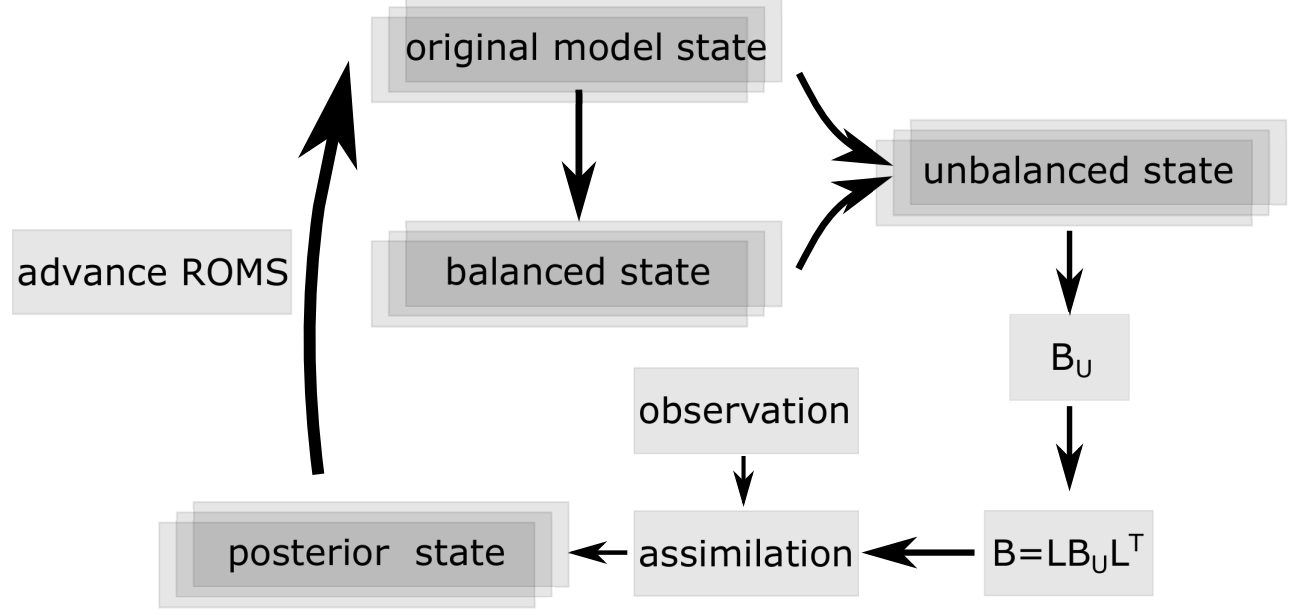

Figure 1: A schematic description of the balanced data assimilation system. 

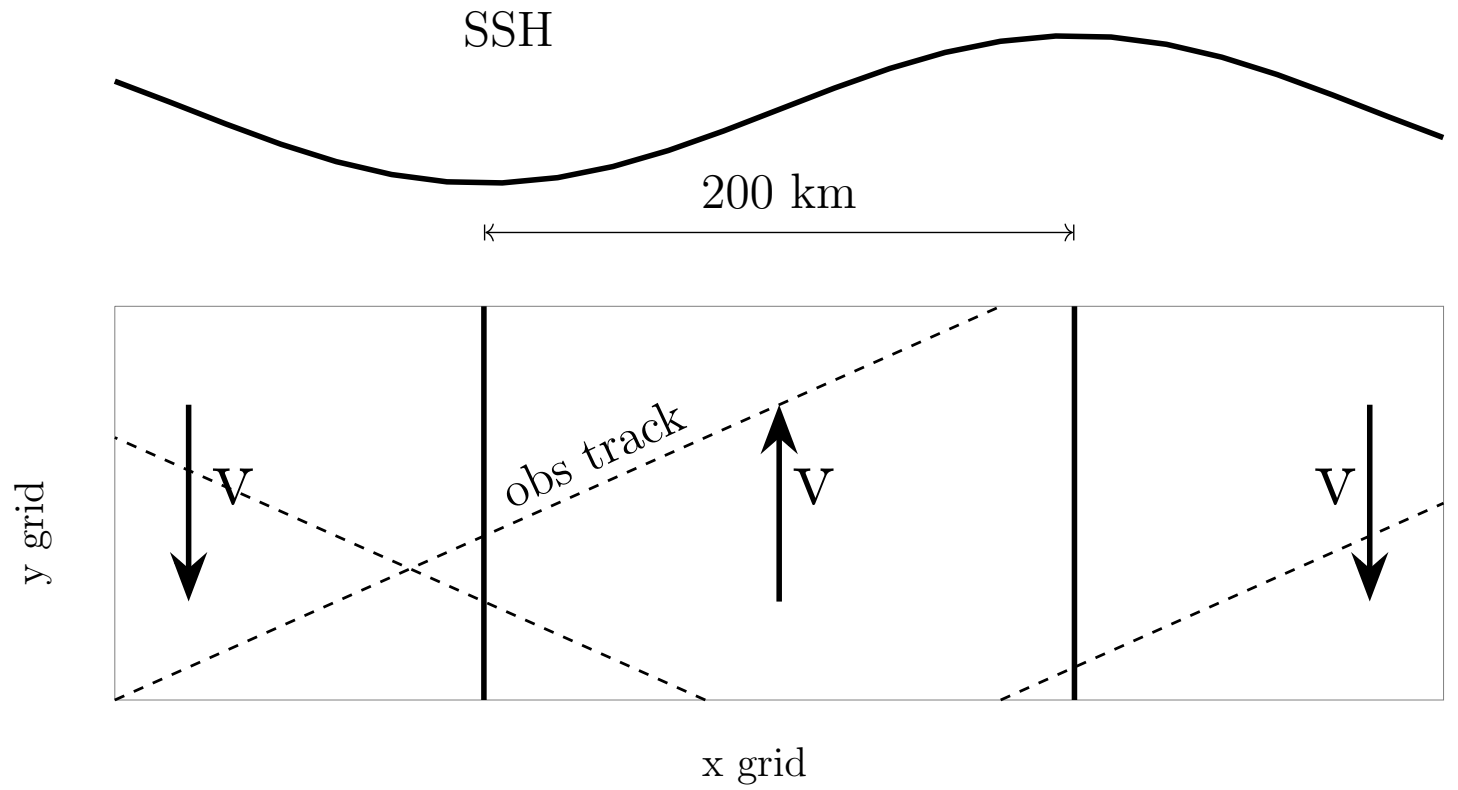

Figure 2: A schematic description of the shallow water model. 

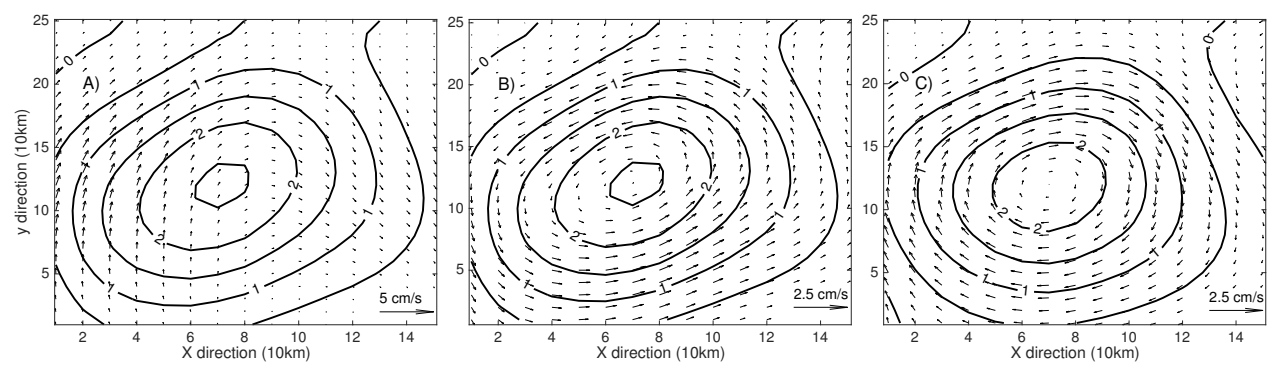

Figure 3: Snapshots of A) SSH (contour) and velocities (quiver) from the unbalanced experiment, B) SSH and ageostrophic velocities from the unbalanced experiment and C) $\mathrm{SSH}$ and velocities from the balanced experiment. The units of SSH are $\mathrm{cm}$. 

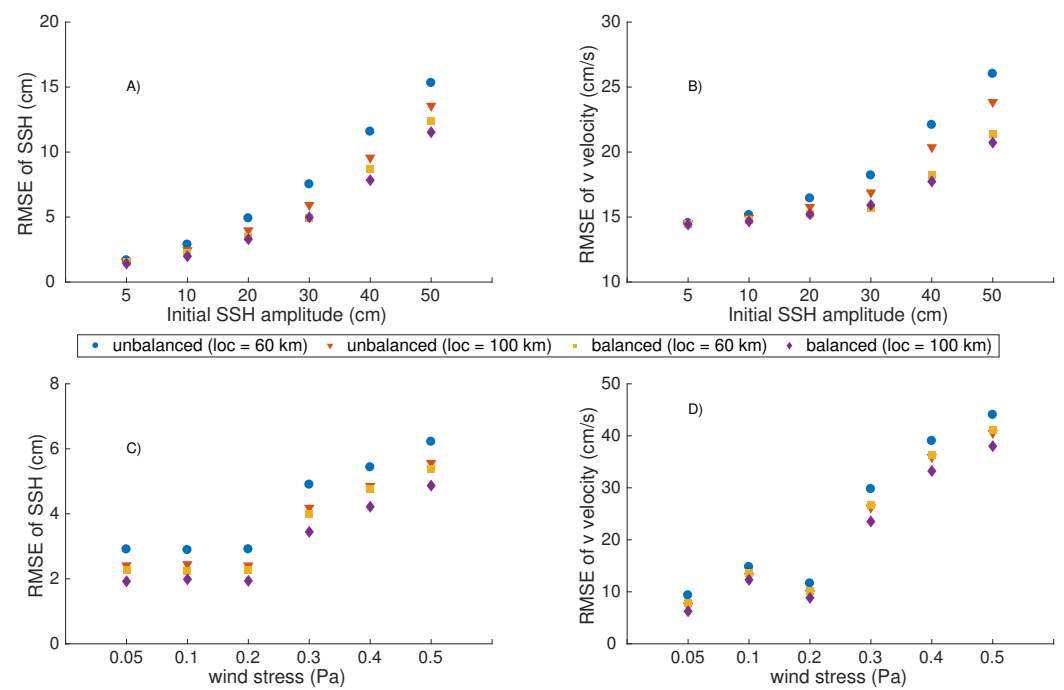

Figure 4: RMSE of SSH (A and C) and meridional velocity $v$ (B and D) with varying initial $\eta$ amplitude (upper panel) and wind forcing (lower panel) in the idealised case. 

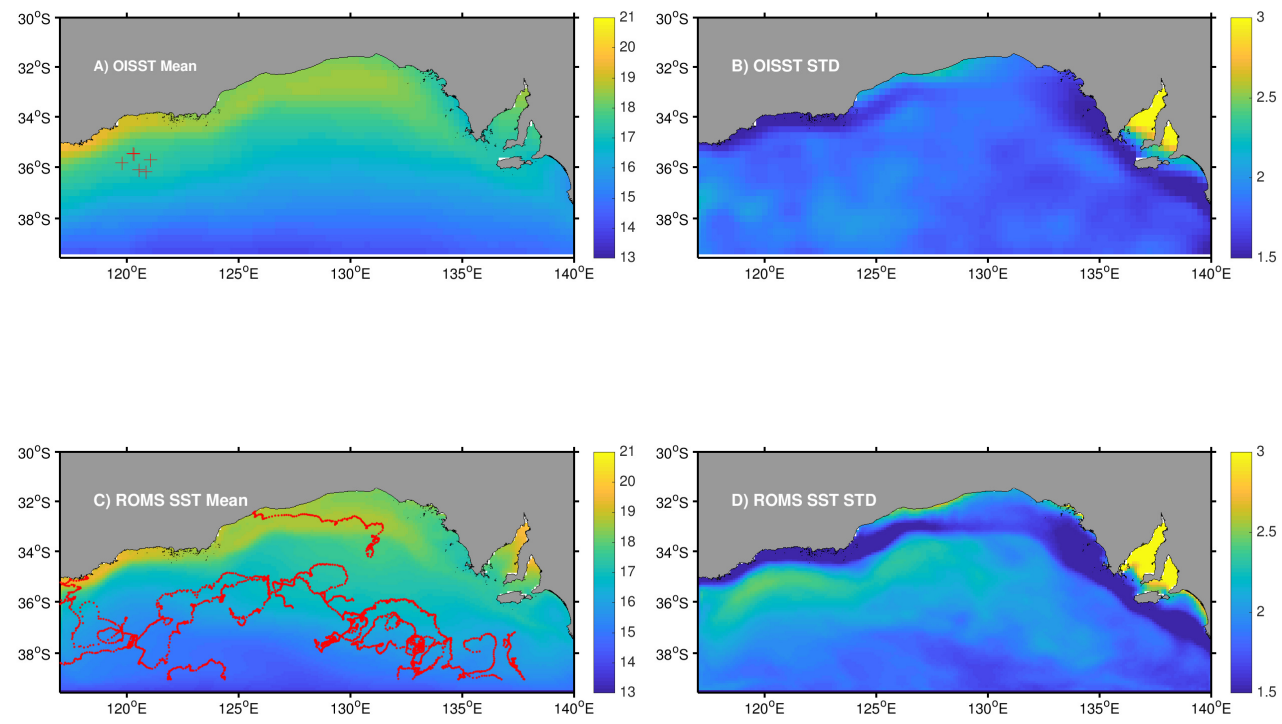

Figure 5: ROMS simulated SST mean and standard deviation compared to OISST observation. The units are ${ }^{\circ} \mathrm{C}$. The crosses and dots in A) and C) represent the locations of ARGO floats and drifters. 

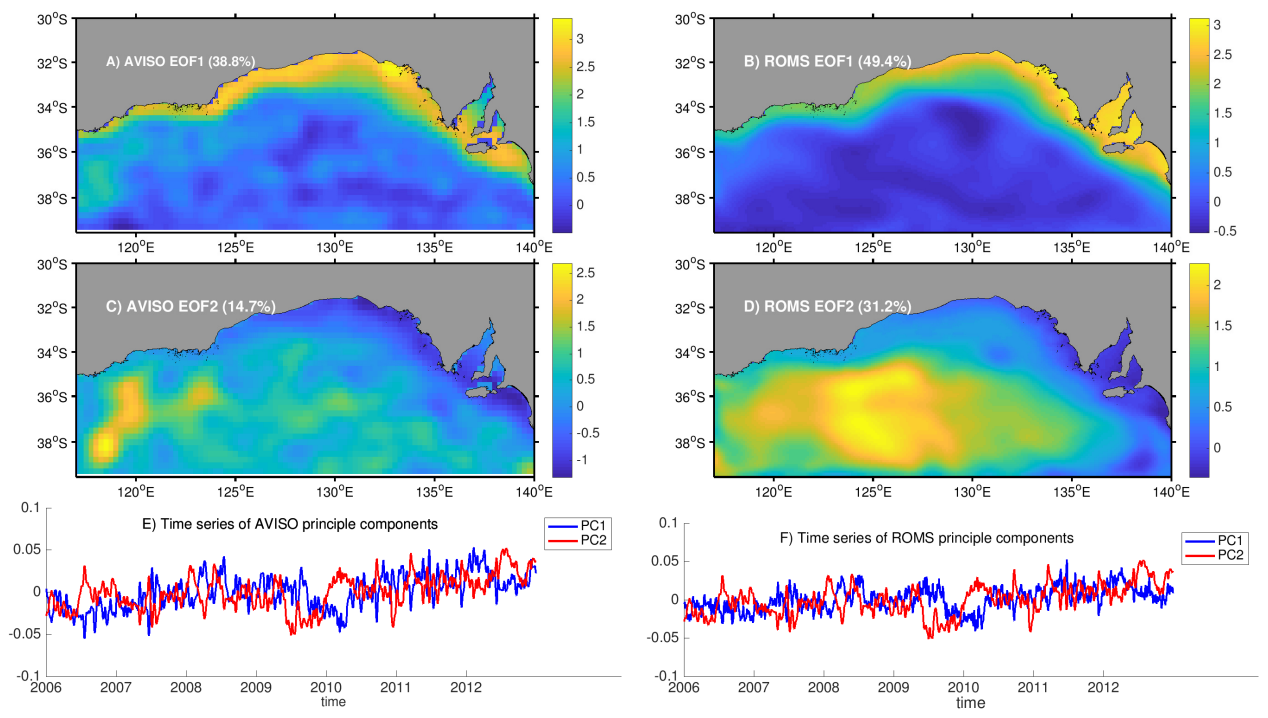

Figure 6: The first 2 EOFs of deseasonalised (left panel) AVISO daily Sea Level Anomaly (SLA) data and (right panel) ROMS simulated SLA between 2006 and 2012. The units are $\mathrm{cm}$. 

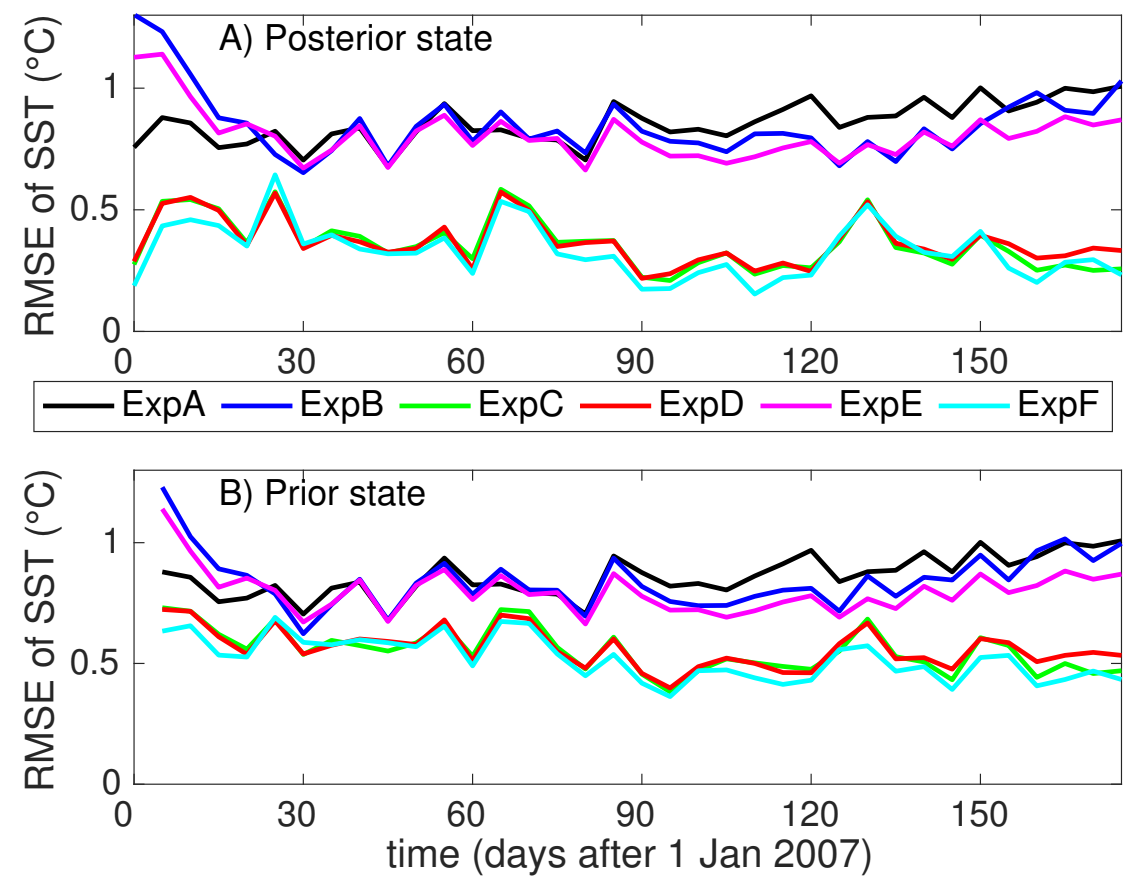

Figure 7: ROMS simulated SST mean and standard deviation compared to OISST observation. The units are ${ }^{\circ} \mathrm{C}$. 


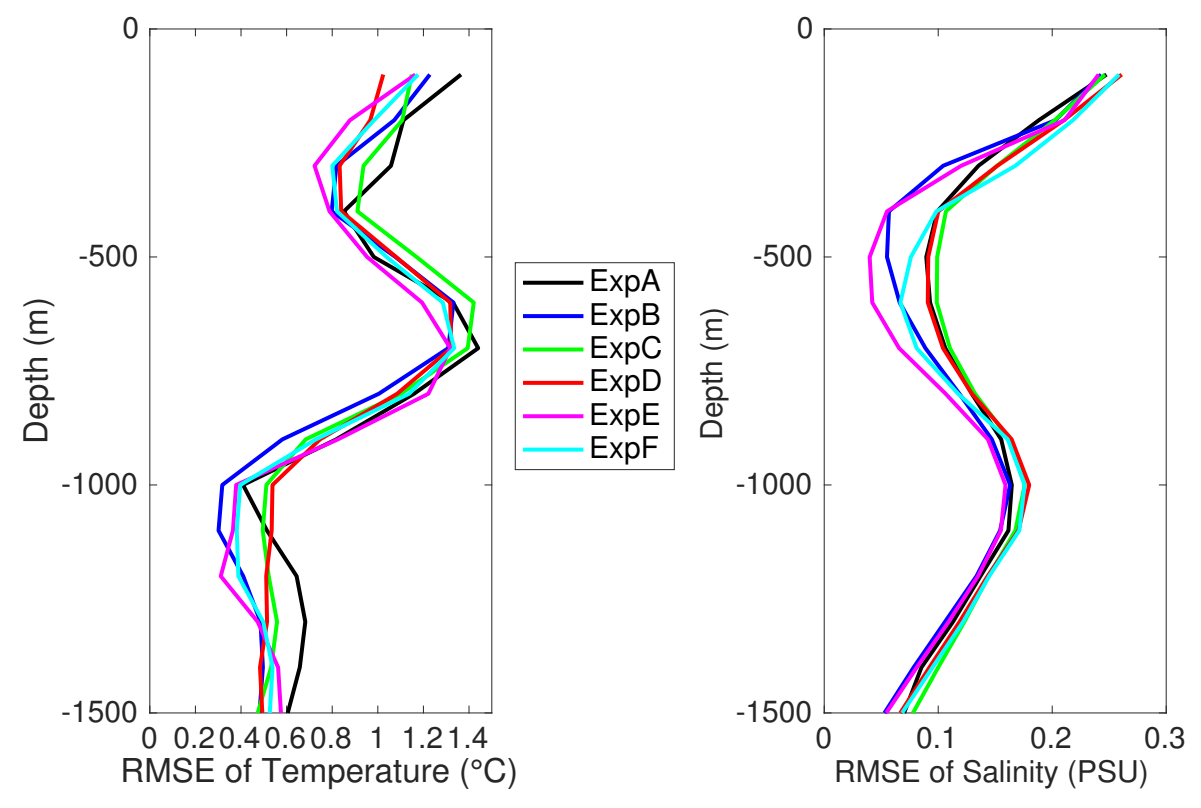

Figure 8: RMSE of subsurface temperature vertical profile. 

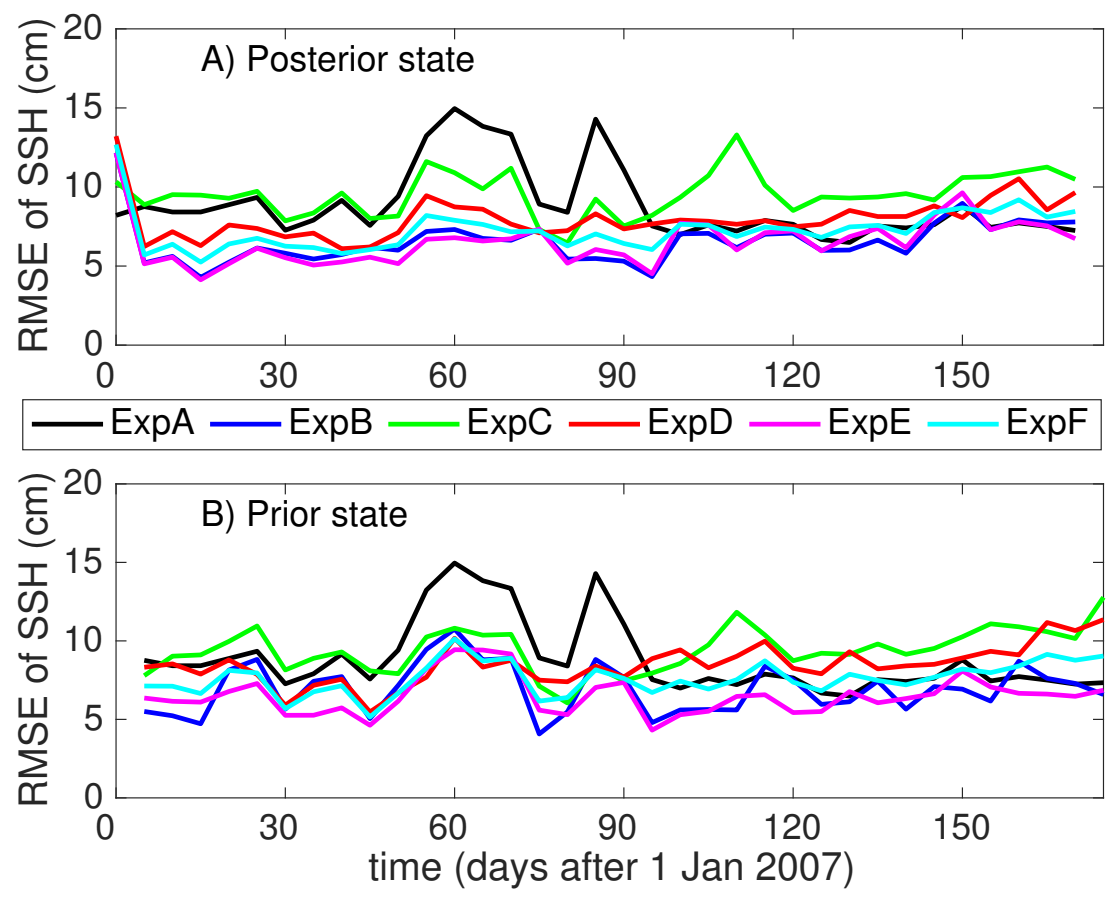

Figure 9: RMSE of SSH for A) posterior state (i.e., the analysis) and B) prior state (i.e., the 5 -day forecast). The units are $\mathrm{cm}$. 

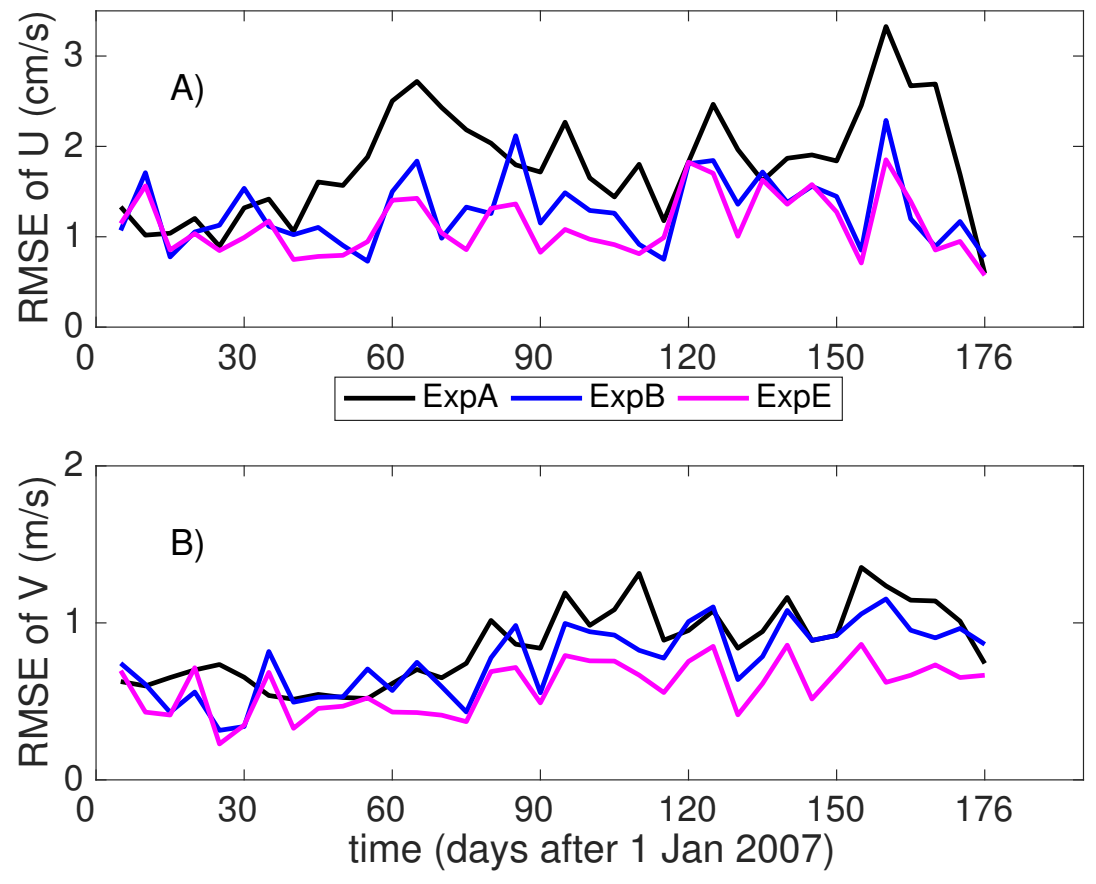

Figure 10: RMSE of top 30m A) zonal and B) meridional currents compared with OSCAR. The units are $\mathrm{cm} / \mathrm{s}$. 

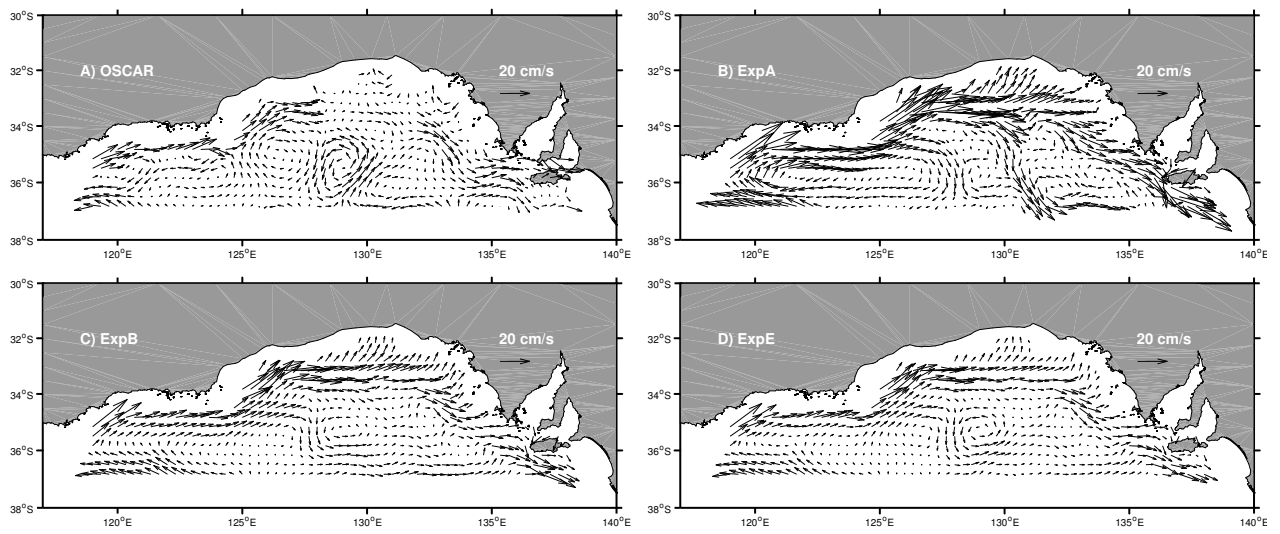

Figure 11: A comparison of top 30m currents of A) OSCAR dataset, B) ROMS control run, C) SSH assimilation without balance operator and D) SSH assimilation with balance operator 

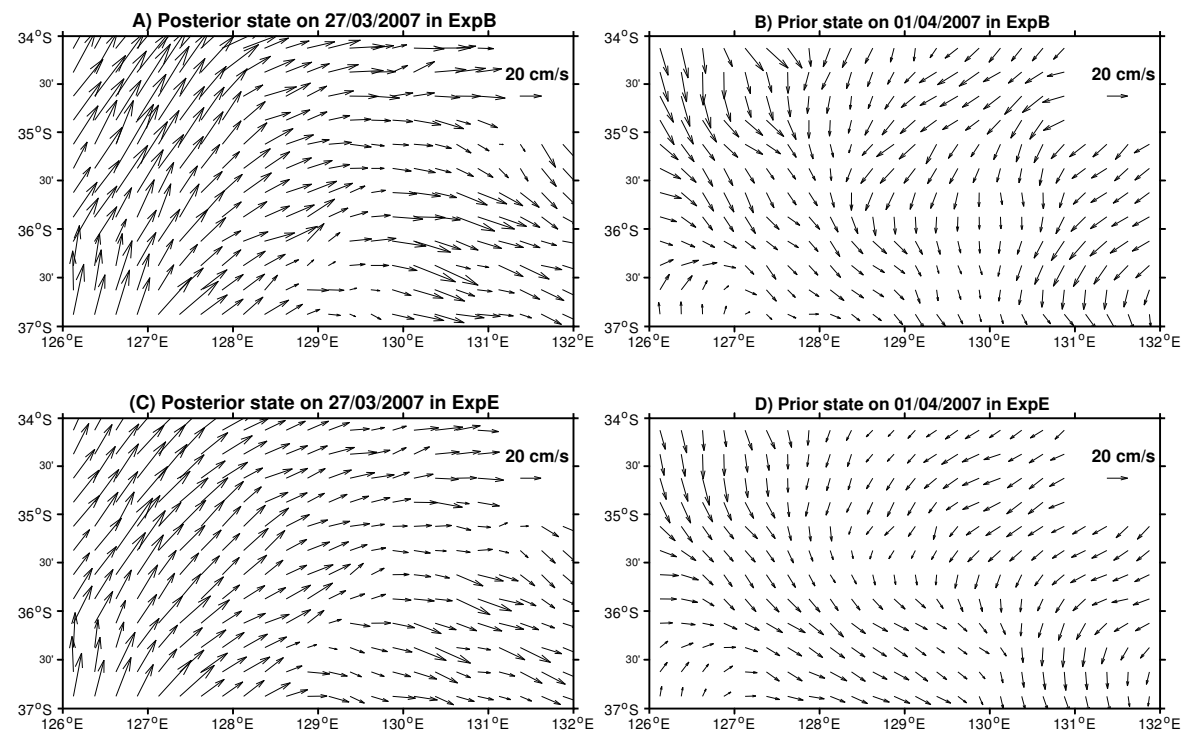

Figure 12: Snapshots of surface ageostrophic currents of posterior state on 27/03/2007 and prior state on 01/04/2007 in ExpB and ExpE 

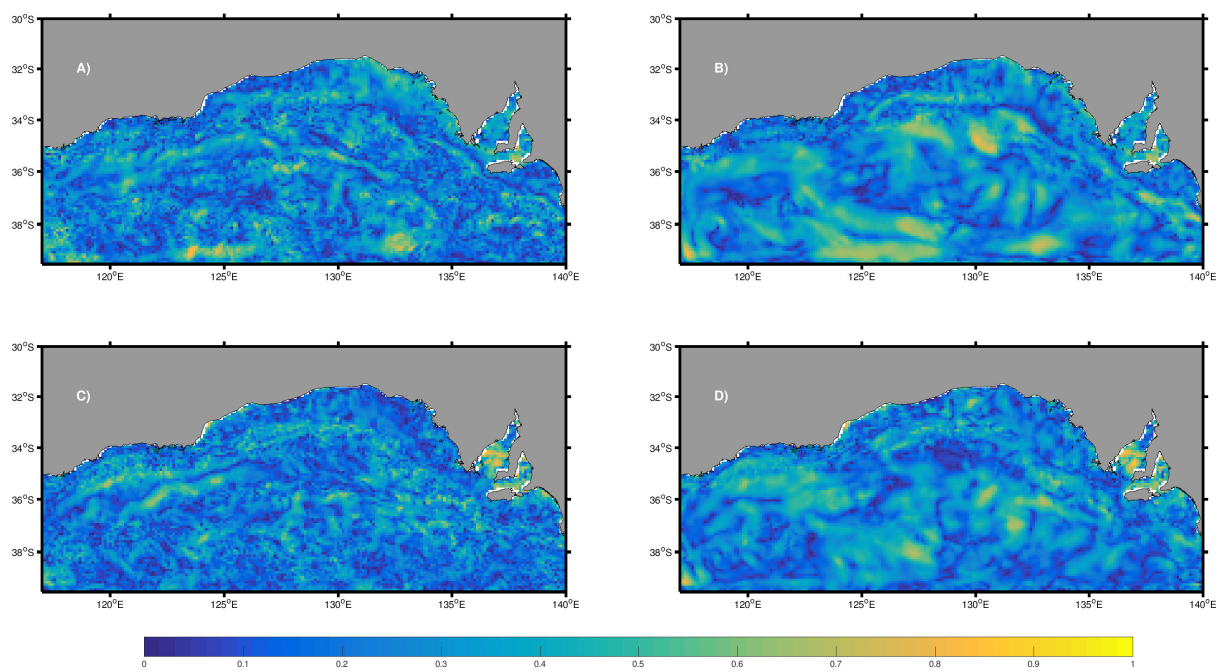

Figure 13: Ensemble correlations between surface variables and surface and subsurface currents on 30 January 2007 in ExpB. A) Correlation between SST and 5m currents, B) Correlation between SST and 200m currents, C) Correlation between SSH and $5 \mathrm{~m}$ current, D) A) Correlation between SSH and 200m currents 


\section{Appendix A. Representation of the linear balance operator and background error covariance matrix}

As described in Section 2.1, each variable except $T$ is decomposed into unbalanced and balanced components and the balanced part is computed from other variables using the linear balance operator $L$. The explanation of $L$ is given in this appendix.

Weaver et al. (2005) proposed to use 3 balance constraints, the temperature - salinity balance, hydrostatic balance and geostrophic balance for ocean data assimilation, and the variables and their increments can be decomposed as following,

$$
\delta T=\delta T,
$$

where

$$
\begin{gathered}
\delta S=\delta S_{B}+\delta S_{U}=L_{S T} \delta T+\delta S_{U} \\
\delta \eta=\delta \eta_{B}+\delta \eta_{U}=L_{\eta \rho} \delta \rho+\delta \eta_{U} \\
\delta u=\delta u_{B}+\delta u_{U}=L_{u p} \delta p+\delta u_{U} \\
\delta v=\delta v_{B}+\delta v_{U}=L_{v p} \delta p+\delta v_{U}
\end{gathered}
$$

The first constraint (Eq. A.1) is the $T-S$ relationship which regulates the property of the water mass. It is based on the property of the prior ensemble,

$$
\delta S_{B}=r \frac{d S}{d z} \frac{d z}{d T} \delta T,
$$

where $r=1-e^{-z / z_{M}}$ is defined the same as in the ROMS-4DVAR (Moore et al., 2011c) package, $z$ is the vertical coordinate and $z_{M}$ is the mixed layer depth. The mixed layer depth is set to a constant value $(200 \mathrm{~m})$. In this region, the mixed layer depth is between $50 \mathrm{~m}$ to $120 \mathrm{~m}$ but under some extreme events (e.g., storms) it can be up to about $200 \mathrm{~m}$. For a smaller actual mixed layer depth, this assumption will overweight the balanced salinity below the mixed layer. The density (Eq. A.5) is a function of temperature and salinity and is calculated using a linearised version of the equation of state described by Jackett and Mcdougall (1995), where $L_{\rho T}=\rho_{0} * \alpha$ and 
$L_{\rho S}=\rho_{0} * \beta$. The reference density $\rho_{0}$ is set to $1025 \mathrm{~kg} / \mathrm{m}^{3}$ and $\alpha$ and $\beta$ is the thermal expansion and saline contraction coefficients, respectively.

The second constraint is the hydrostatic balance which computes the balanced (baroclinic) sea level from the density and, therefore, temperature and salinity. The complete expression of the baroclinic relationship is an elliptic equation (Weaver et al., 2005),

$$
\nabla \cdot H \nabla \delta \eta_{B}=-\nabla \cdot \int_{z=-H}^{0} \int_{z^{\prime}=z}^{0}\left(\nabla \delta \rho\left(z^{\prime}\right) / \rho_{0}\right) d z^{\prime} d z,
$$

where $H$ is the ocean depth. Eq. A.8 excludes the influence of advection, assuming it is not important. However, this may be problematic in the areas where the contribution of advection is great such as the coastal region. To reduce the computational cost, a simplified version of Eq. A.8 is used in this paper by assigning a 'depth of no motion' $z_{0}$ (1000 $\mathrm{m}$ in this paper),

$$
\delta \eta_{B}=\int_{z^{\prime}=z_{0}}^{0}\left(\delta \rho\left(z^{\prime}\right) / \rho_{0}\right) d z^{\prime},
$$

and in regions where the ocean is shallower than $z_{0}$ Eq. A.9 is integrated from the bottom.

Then the pressure at depth $z$ is computed by integrating the hydrostatic equation from $z$ to the surface,

$$
\delta p(z)=\int_{z^{\prime}=z}^{0}\left(\delta \rho\left(z^{\prime}\right) g\right) d z^{\prime}+\rho_{0} g \delta \eta,
$$

The third balance operator is the geostrophic balance, which computes the increments of $u$ and $v$ from sea level.

$$
\begin{aligned}
& \delta u_{B}(z)=-\frac{1}{\rho_{0} f} \frac{\partial \delta p(z)}{\partial y} \\
& \delta v_{B}(z)=\frac{1}{\rho_{0} f} \frac{\partial \delta p(z)}{\partial x}
\end{aligned}
$$

where $f$ is the Corriolis force, $x$ and $y$ are the horizontal coordinates. The continuity constraint is not explicitly implemented, but it is satisfied above the depth of no motion because the balanced velocity is in geostrophic balance with $\eta$. 
${ }_{942}$ By using the above three balance constraints, the balanced component 943 can be computed. In addition, we assume that the unbalanced components 944 are uncorrelated with each other and thus the unbalanced error covariance 945 is a block diagonal,

$$
B_{u}=\left(\begin{array}{ccccc}
B_{T} & 0 & 0 & 0 & 0 \\
0 & B_{S} & 0 & 0 & 0 \\
0 & 0 & B_{\eta} & 0 & 0 \\
0 & 0 & 0 & B_{u} & 0 \\
0 & 0 & 0 & 0 & B_{v}
\end{array}\right)
$$

946 where $B_{x}$ is the error covariance of the unbalance component of variable $x$. ${ }_{947}$ The linear balance operator matrix is a lower triangular matrix

$$
L=\left(\begin{array}{ccccc}
I & 0 & 0 & 0 & 0 \\
L_{S T} & I & 0 & 0 & 0 \\
L_{\eta T} & L_{\eta S} & I & 0 & 0 \\
L_{u T} & L_{u S} & L_{u \eta} & I & 0 \\
L_{v T} & L_{v S} & L_{u \eta} & 0 & I
\end{array}\right)
$$

where,

$$
\begin{gathered}
L_{\eta T}=L_{\eta \rho} L_{\rho T}, \\
L_{\eta S}=L_{\eta \rho} L_{\rho S}, \\
L_{u T}=L_{u p} L_{p \rho} L_{\rho T}, \\
L_{u S}=L_{u p} L_{p \rho} L_{\rho S}, \\
L_{u \eta}=L_{u p} L_{p \eta}, \\
L_{v T}=L_{v p} L_{p \rho} L_{\rho T}, \\
L_{v S}=L_{v p} L_{p \rho} L_{\rho S}, \\
L_{v \eta}=L_{v p} L_{p \eta} .
\end{gathered}
$$

948 Therefore the background error covariance matrix is,

$$
L B_{U} L^{T}=\left(\begin{array}{ccccc}
B_{T T} & B_{S T}^{T} & B_{\eta T}^{T} & B_{u T}^{T} & B_{v T}^{T} \\
B_{S T} & B_{S S} & B_{\eta S}^{T} & B_{u S}^{T} & B_{v S}^{T} \\
B_{\eta T} & B_{\eta S} & B_{\eta \eta} & B_{u \eta}^{T} & B_{v \eta}^{T} \\
B_{u T} & B_{u S} & B_{u \eta} & B_{u u} & B_{v u}^{T} \\
B_{v T} & B_{v S} & B_{v \eta} & B_{v u} & B_{v v}
\end{array}\right),
$$


where

$$
\begin{gathered}
B_{T T}=B_{T}, \\
B_{S T}=L_{S T} B_{T}, \\
B_{\eta T}=L_{\eta T} B_{T}, \\
B_{u T}=L_{u T} B_{T}, \\
B_{v T}=L_{v T} B_{T}, \\
B_{S S}=L_{S T} B_{T} L_{S T}^{T}+B_{S}, \\
B_{\eta S}=L_{\eta S} B_{S}, \\
B_{u T}=L_{u T} B_{T}, \\
B_{v T}=L_{v T} B_{T}, \\
B_{\eta \eta}=L_{\eta T} B_{T} L_{\eta T}^{T}+L_{\eta S} B_{S} L_{\eta S}^{T}+B_{\eta}, \\
B_{u \eta}=L_{u T} B_{T} L_{\eta T}^{T}+L_{u S} B_{S} L_{\eta S}^{T}+L_{u \eta} B_{\eta}, \\
B_{v \eta}=L_{v T} B_{T} L_{\eta T}^{T}+L_{v S} B_{S} L_{\eta S}^{T}+L_{v \eta} B_{\eta}, \\
B_{u u}=L_{u T} B_{T} L_{u T}^{T}+L_{u S} B_{S} L_{u S}^{T}+L_{u \eta} B_{\eta} L_{u \eta}^{T}+B_{u}, \\
B_{v u}=L_{v T} B_{T} L_{u T}^{T}+L_{v S} B_{S} L_{u S}^{T}+L_{v \eta} B_{\eta} L_{u \eta}^{T}, \\
B_{v v}=L_{v T} B_{T} L_{v T}^{T}+L_{v S} B_{S} L_{v S}^{T}+L_{v \eta} B_{\eta} L_{v \eta}^{T}+B_{v} .
\end{gathered}
$$

This background error covariance matrix is used in all the balanced data assimilation experiments to compute the updated mean and covariance.

\section{Appendix B. Implementation of the linear balance operator in EAKF}

The EAKF algorithm (Anderson, 2001) is used in this work. The main difference of EAKF and the conventional EnKF is that in EAKF, an adjustment matrix $A$ is used to compute the the posterior covariance so that

$$
B^{a}=A^{T} B^{f} A
$$

and the posterior state is

$$
x^{a}=A\left(x^{f}-\overline{x^{f}}\right)+\overline{x^{a}} .
$$


956 In this work the adjustment matrix is the same with that described by An957 derson $(2001,2003)$ and Eq. B.2 becomes

$$
x^{a}=A L_{B}\left(x_{u}^{f}-\overline{x_{u}^{f}}\right)+\overline{x^{a}} .
$$

958 In the balanced data assimilation experiments, the linear regression mul959 tivariate analysis procedure (Anderson, 2003) provided in DART is not used 960 and the unobserved variables is updated through Eq. B.3. This procedure 961 can only be performed in the model space so it is slower than the original 962 two-step EAKF algorithm. 